\title{
How to Achieve Swift Resilience: the Role of Digital Innovation Enabled Mindfulness
}

\author{
Dandan Ye ${ }^{1}$ Martin J. Liu' ${ }^{1}$. Jun Luo ${ }^{1} \cdot$ Natalia Yannopoulou²
}

Accepted: 10 November 2021

( ) The Author(s), under exclusive licence to Springer Science+Business Media, LLC, part of Springer Nature 2022

\begin{abstract}
Contributed to by the prevalence of digital technology, various cases of new ventures achieve resilience quickly despite experiencing hardship. Growing attention has been devoted to mindfulness—being alert and acting swiftly—to explain recovery. Scholars have primarily focused on mindful resource preparation pre-crisis. Nevertheless, how to mindfully organize resources as a crisis occurs remains under-explored. Based on an inductive study of a ride-sharing vehicle venture, which rapidly became an open service platform during the COVID-19 pandemic in China, we develop a framework termed "swift resilience" to understand how new ventures mindfully organize resources, driven by digital innovation. In particular, we critically trace three mechanisms - "data-driven stretching," "collective sharing," and "rapid pivoting"—and develop a process model to understand how new ventures build swift resilience. Our emerging findings shed light on the scholarship of organizational resilience, mindfulness, and digital entrepreneurship, and provide guidance to managers on achieving resilience quickly.
\end{abstract}

Keywords Digital Innovation · Mindful Organizing $\cdot$ Mindfulness $\cdot$ Organizational resilience

\section{Introduction}

The unexpected crisis of the COVID-19 pandemic led to the collapse of many business activities and caused vast economic breakdowns worldwide (Badkar \& Greeley, 2020). According to Statista, $72 \%$ of new ventures have seen their revenues decline since COVID-19 hit, as they were vulnerable to the shock brought on by the pandemic (McCarthy, 2020). However, anecdotal evidence has indicated that, despite these challenges, some innovative new ventures have

Martin J. Liu

martin.liu@nottingham.edu.cn

Dandan Ye

dandan.ye@nottingham.edu.cn

Jun Luo

maria.luo@nottingham.edu.cn

Natalia Yannopoulou

natalia.yannopoulou@newcastle.ac.uk

1 Nottingham University Business School China, University of Nottingham Ningbo China, 199 Taikang East Road, Ningbo 315100, China

2 Newcastle University Business School, 5 Barrack Rd, Newcastle upon Tyne NE1 4SE, U.K. creatively deployed resources and quickly achieved organizational resilience, defined as "positively adjust and maintain functioning prior to, during, and following adversity" (Williams et al., 2017, p. 742; see also Mckinsey, 2021). Building resilience quickly is particularly important for new ventures with few resources since they are less likely to withstand adversity for long periods of time (Pillai et al., 2020). Moreover, faster recoveries protect ventures from ongoing damage (DesJardine et al., 2019) that significantly impacts new ventures' survival and growth (Herbane, 2019).

Emerging literature has begun to examine how ventures recover quickly (DesJardine et al., 2019; Gölgeci \& Kuivalainen, 2020), make decisions without delay (Menéndez Blanco \& Montes-Botella, 2017; Weick \& Sutcliffe, 2007), and respond more rapidly (Herbane, 2015; Hillmann \& Guenther, 2021). Growing attention has been devoted to how mindfulness - being alert and acting swiftly—of emerging issues (Vogus \& Sutcliffe, 2012; Weick et al., 1999) influences a quick response and faster recovery (Linnenluecke, 2017; Singh et al., 2021). Scholars have typically put weight on how mindfully preparing resources such as relationships (Powley, 2009) and risk-averting infrastructures (Ramezani \& Camarinha-Matos, 2020) facilitate ventures to maintain organizational function. Nevertheless, the assumption of 
mindful anticipation pre-crisis has two limitations. First, mindfully prepared resources pre-crisis might not necessarily be what a venture needs during challenging times (Battisti \& Deakins, 2017). Second, even for ventures that have specific resources in reserve, these resources are highly vulnerable and more likely to be lost when the complexity and uncertainty level of the crisis is high (Doern, 2016). Indeed, scholars have indicated the tendency of transitioning from dependence on mindful preparing to mindful organizing as the crisis occurs (Williams et al., 2017). The alternative method of mindful organizing - swiftly and consciously generating a variety of forms of resource development and deployment-might offer a faster, more fundamental solution to resilience. An initial attempt has been made by Zafari et al. (2020) to mindfully manage external relationships during a crisis. However, mindful managing of relational resources might require a relatively long period to come to fruition; thus, the process by which resilience can be achieved quickly remains under-explored. Moreover, the prevalence of digital innovation, with its particular characteristics (Huang et al., 2017; Yoo et al., 2012, 2010), might significantly change the relationship between mindfulness and resilience. Therefore, it is worthwhile to investigate mindful resource organizing by taking into account digital innovation and its impact on resilience.

Mindful resource organizing enabled by digital innovation is theoretically and practically essential. Aided by the prevalence of digital technologies such as artificial intelligent (AI) driven adaptive learning technologies, algorithms, and so on, innovative ventures are more likely to develop and deploy resources quickly - and this has been particularly true in the ever-changing environment of the COVID19 pandemic (Mckinsey, 2021). As such, new ventures that mindfully organize resources could enjoy a higher possibility of building resilience swiftly. Notably, the prevalence of digital innovation, which is defined as "the recombination of digital components in a layered, modular architecture to create new values" (Huang et al., 2017, p.302), especially with its unique characteristics, offers new ventures ample opportunities to change the process, outcome, and actors pertaining to the mindful organization of resources, ultimately resulting in building resilience quickly. Since most digital products remain reprogrammable (Yoo et al., 2012) and generative (Wareham et al., 2014; Yoo et al., 2010), ventures can be open to recombination and interpretation of existing operations and can swiftly extend their functional scope, features, and values with negligible cost. Furthermore, design flexibility of digital innovation views entrepreneurial opportunities as emergent and rescopes them mindfully (Henfridsson et al., 2014), thus triggering the market-shaping result (Garud et al., 2008; Lusch \& Nambisan, 2015). Moreover, the convergence of digital innovation (Henfridsson \& Bygstad, 2013; Yoo et al. 2012) enables the venture to be "less predefinition" (Nambisan, 2017, p. 1030), thus significantly expanding the scope and scale of actors' mindful behaviors. Yet, while digital innovation is a potential critical stimulator of various mindful behaviors-which are a significant driver for new ventures' robust transformation during a crisis-the process of how to utilize digital innovation to facilitate resilience is under-researched. This raises the research question: How can ventures engage in mindful behaviors driven by digital innovation, which can quickly facilitate resilience?

Given the limited theory and empirical evidence,we adopt a single-case theory-building approach (Gioia\& Chittipeddi, 1991; Gioia et al., 2013; Langley, 1999; Strauss\& Corbin, 1998). Drawing on definitions of organizational resilience (Lengnick-Hall \& Beck, 2005; Shepherd, 2020; Williamset al., 2017), wepropose the term swift resilience to capture the dynamic process throughwhich mindful resource organizing behaviors could be developed when digitalinnovation is at the core, quickly resulting in a new and better equilibrium. We undertake an in-depth case study of a venture called Digital ICAR (a ride-sharingvehicle business) based on its invested business intelligence systems, analyticalgorithms, platforms, and so on. Since February 2020, the venture has quicklyand efficiently resumed and revised its business thanks to its digitaltechnologies. Moreover, it launched numerous business trials in less than amonth to respond to users' desire for exclusive travel space. Toward the end of 2020, this venture achieved exponential growth in its revenues and user baseand transformed from a pure self-service leasing platform to an open-serviceplatform. We select Digital ICAR as an extreme case (Gerring, 2007) toinvestigate our research question because it has achieved swiftresilience-rapid transformation in less than one year. The venture provides anexcellent setting to elaborate the process by which digital innovationfacilitates new ventures to engage in mindful resource organizing behaviors.

We contribute to the nexus of organizational resilience, mindfulness, and digital entrepreneurship literature in several ways. First, our core contribution is the theoretical framework for swift resilience-a dynamic process in which digital innovation catalyzes mindful resource organizing behaviors that allow ventures to build a new equilibrium quickly. Departing from the dominating mindful resource preparation assumption (Powley, 2009; Ramezani \& Camarinha-Matos, 2020; Weick \& Sutcliffe, 2007), our study illuminates a novel pathway that contains three main mechanisms for ventures to rapidly transform their business despite challenges: data-driven stretching, collective sharing, and rapid pivoting. Second, we contribute to mindfulness literature (Sutcliffe et al., 2016; Weick \& Roberts, 1993; Weick $\&$ Sutcliffe, 2006) by extending knowledge of its behavioral process, outcome, and actors. Resonating with the crosslevel and emergent perspective of mindfulness (Carlo et al., 2012), the nuanced view of how intra-organizational and 
inter-organizational mindful organizing interplay ultimately facilitates the venture to achieve a transformative outcome. Third, we highlight how our insights may hold potential for the burgeoning identity change in the entrepreneurship literature (Powell \& Baker, 2014; Williams \& Shepherd, 2016a, 2016 b). We confirm that ventures with prosocial motivation and that foster flexible interdependency with external stakeholders are more likely to change identity without penalty.

The remainder of this paper proceeds as follows: We first develop our conceptual basis of swift resilience by theoretically reviewing the literature on organizational resilience, explaining how digital innovation potentially disrupts mindfulness. We then discuss our settings and methods for data collection and analysis. In the next section, we present our findings of digital innovation enabled mindfulness, then develop a framework connecting the empirical evidence of mindfulness and swift resilience. This is followed by the respective theoretical and practical implications. We conclude the paper by outlining the study's limitations.

\section{Conceptual Basis}

\subsection{Organizational Resilience and Mindfulness}

Organizational resilience-wherein an organization interacts with its environment and positively maintains and adjusts its functions (Williams et al., 2017)—has emerged as one of the most important and widely applied concepts that are receiving growing attention from management researchers. More recently, attention has turned to how to build resilience quickly (DesJardine et al., 2019; Haase \& Eberl, 2019; Herbane, 2015, 2019), with an emphasis on quick recovery (DesJardine et al., 2019; Gölgeci \& Kuivalainen, 2020), immediate identification of risk and opportunities (Conz \& Magnani, 2020; El Baz \& Ruel, 2021; Morrish \& Jones, 2020), quick decisions without delay (Menéndez Blanco \& Montes-Botella, 2017; Weick \& Sutcliffe, 2007), and faster response (Chesbrough, 2020; Gittell et al., 2006). The ability to build resilience quickly is essential for ventures because the quicker a venture takes action, the more likely it is to be able to reduce the severity of loss and protect itself from ongoing damage (DesJardine et al., 2019). This is particularly true for new ventures, as long-term recovery may be exhausted by their limited resources (Pillai et al., 2020) and substantially influence survival prospects and business continuity (Herbane, 2019).

Nascent scholars have emphasized the importance of mindfulness-defined as the awareness of discriminatory details about emerging issues and acting swiftly in response to these details (Vogus \& Sutcliffe, 2012; Weick et al., 1999)_facilitating resilience quickly (Linnenluecke, 2017; Singh et al., 2021; Sutcliffe et al., 2016; Williams et al., 2017). As summarized in Table 1, studies have typically focused on the anticipation aspect of mindfulness to investigate how mindfully prepared resources-such as relational reserves (DesJardine et al., 2019; Gölgeci \& Kuivalainen, 2020; Powley, 2009), risk averting infrastructures (Beigi,

Table 1 Research streams on rapidly building resilience

\begin{tabular}{|c|c|c|}
\hline Research stream & Definition & Example references \\
\hline Relational reserves & $\begin{array}{l}\text { Activities by which ventures leverage pre-crisis interdepend- } \\
\text { ency between internal and external stakeholders to fulfill } \\
\text { the needs of a quick information flow and quick recovery to } \\
\text { pre-crisis performance }\end{array}$ & $\begin{array}{l}\text { DesJardine et al. (2019) } \\
\text { Gölgeci and Kuivalainen (2020) } \\
\text { Leguizamon et al. (2016) } \\
\text { Powley (2009) }\end{array}$ \\
\hline Risk-averting infrastructures & $\begin{array}{l}\text { Strategic risk planning through which ventures resume opera- } \\
\text { tions and heal immediately by identifying, assessing, mitigat- } \\
\text { ing, and controlling risks quickly and in advance }\end{array}$ & $\begin{array}{l}\text { Beigi (2014) } \\
\text { Hales and Chakravorty (2016) } \\
\text { Herbane (2015) } \\
\text { Parker and Ameen (2018) } \\
\text { Ramezani and Camarinha-Matos (2020) }\end{array}$ \\
\hline $\begin{array}{l}\text { Diversified products and } \\
\text { markets }\end{array}$ & $\begin{array}{l}\text { The process by which ventures quickly identify opportunities } \\
\text { and adapt their product offerings via restoring their product } \\
\text { flow and creating variants to serve changing market needs }\end{array}$ & $\begin{array}{l}\text { Conz and Magnani (2020) } \\
\text { Gunasekaran et al. (2011) Markman } \\
\text { and Venzin (2014) } \\
\text { Morrish and Jones (2020) }\end{array}$ \\
\hline Managerial experience & $\begin{array}{l}\text { The decisions performed without delay by managers and } \\
\text { employees utilizing their domain expertise and past experi- } \\
\text { ence to be adept at responding and recovering quickly }\end{array}$ & $\begin{array}{l}\text { Kahn et al. (2018) } \\
\text { Menéndez Blanco and Montes-Botella (2017) } \\
\text { Weick and Sutcliffe (2007) }\end{array}$ \\
\hline Financial abundance & $\begin{array}{l}\text { Sufficiently flexible activities by which ventures buffer the } \\
\text { impact of environmental jolts and deploy faster responses to } \\
\text { unanticipated events based on cash flow and low debt }\end{array}$ & $\begin{array}{l}\text { Bartz and Winkler (2016) } \\
\text { Gittell et al. (2006) } \\
\text { McFarlane and Norris (2006) }\end{array}$ \\
\hline
\end{tabular}


2014; Ramezani \& Camarinha-Matos, 2020), diversified products and markets (Markman \& Venzin, 2014; Morrish \& Jones, 2020), managerial experience (Li et al., 2016; Menéndez Blanco \& Montes-Botella, 2017), and financial abundance (Bartz \& Winkler, 2016; Gittell et al., 2006)—contribute to highly reliable operations and resilience during a crisis (Vogus et al., 2014; Weick \& Sutcliffe, 2007). In particular, the relational reserves stream focuses more on the interdependency between internal and external stakeholders during periods pre-crisis. For instance, Powley (2009) showed that organization members who usually consider their colleagues and respond to others are more likely to reach out when a venture is in a critical period of crisis. Likewise, the riskaverting infrastructures stream devotes attention to strategic risk planning, through which ventures can resume operations and heal immediately following crisis. Scholars have argued that organizations that put mindful engineering systems in place pre-crisis are more likely to be resilient during times of crisis (Ramezani \& Camarinha-Matos, 2020). Other streams of literature, such as those on diversified products and markets, have highlighted the importance of the incremental capability of mindfully responding to market needs by adapting product offerings (Morrish \& Jones, 2020). Financial and human capital streams have emphasized the need to ensure the mindful preparedness of sufficient internal resources accumulated prior to crisis (Bartz \& Winkler, 2016; Menéndez Blanco \& Montes-Botella, 2017).

Despite the abundance of literature identified above, insights into how ventures mindfully prepare resources may constitute shortcomings. Two aspects are worth noting. First, given that crises are characterized by high uncertainty and ambiguity (Oehmen et al., 2020), ventures must have the necessary resources prepared and accurately anticipate challenges to meet the disruptive event's requirement. For example, risk anticipation systems for natural disasters such as earthquakes might not be relevant to an altered crisis such as the COVID-19 pandemic. Second, underpinned by the fragility that is experienced during adversity (Bartz \& Winkler, 2016; Lai et al., 2016), ventures are more vulnerable to losing or exhausting reserved resources (e.g., relationships with customers and suppliers) within an ever-changing and sustained crisis (Parker \& Ameen, 2018; Zafari et al., 2020). For example, firms' financial reserves might be used up due to the significant and long-lasting negative effects of COVID-19. To address these issues, many scholars have shifted attention to another aspect of mindfulness - swift actions to cope with crisis in the moment (Linnenluecke, 2017; Williams et al., 2017). This requires ventures to quickly organize resources in order to detect issues, problems, or opportunities as they arise (Ndubisi \& Al-Shuridah, 2019). One pioneering study investigated how mindful relationship management facilitates recovery after a crisis (Zafari et al., 2020). The findings revealed that a combination of trust, doubt, and control might facilitate a venture to mindfully build relationships with external partners. Nevertheless, the mindful relationship-building process could require a relatively long time to come to fruition, and the process by which ventures mindfully organize resources to facilitate resilience quickly remains under-researched. Moreover, the prevalence of digital innovation, with its unique characteristics (Huang et al., 2017; Yoo et al., 2012; Yoo et al., 2010), enables new ventures to quickly engage in various mindful resource organizing behaviors, thus considerably changing the relationship between new ventures and resilience. This suggests the need to revisit the mindfulness literature by taking into account digital innovation.

\subsection{How Digital Innovation Potentially Disrupts Mindfulness}

The substantial advances in digital innovation, namely, "the recombination of digital components in a layered, modular architecture" (Huang et al., 2017, p. 302), have paved the way for firms to mindfully organize large amounts of heterogeneous resources in new ways (Amit \& Han, 2017; Du, 2015; Yoo et al., 2012). Drawing upon leading research in digital innovation, such as that by Yoo et al. (2012), Henfridsson et al. (2014), and Huang et al. (2017), digital innovation can be traced to three essential characteristics: reprogrammabilitythat is, separation of the semiotic function from the physical media (Henfridsson \& Bygstad, 2013; Yoo et al., 2012); convergence - or increasingly bringing previously separate industries together (Henfridsson \& Bygstad, 2013; Yoo et al., 2012); and generativity—comprising self-reinforcement without any input from the originator of the system (Wareham et al., 2014; Yoo et al., 2010). Reprogrammability means that digital technologies become inherently re-combinable with relatively marginal costs (Yoo et al., 2012), further catalyzing abundant opportunities for convergence and generativity. For example, the popularity of intelligent products, such as smartphones, is one case of reprogrammability resulting from the convergence of technologies within previously non-digital physical industries. Moreover, even the smartphones are sold, it is possible for the venture to introduce generative forms of updated versions. Therefore, the characteristics of digital innovation might potentially disrupt mindful organizing in at least two respects.

First, the process and outcomes of mindfulness might be dramatically changed when digital innovation is at the core. Specifically, the distinct qualities of reprogrammability and generativity offer ventures ample opportunities to mindfully recombine and reintegrate large amounts of resources at negligible marginal cost (Briel et al., 2018; Ortiz-de-Mandojana $\&$ Bansal, 2016). For example, machine learning algorithms make it possible for programs to instantly learn and improve with alertness (Rai et al., 2019), and governance, risk, and compliance software makes ventures less likely to engage in 
mindless decision making (Papazafeiropoulou \& Spanaki, 2016). The resource organizing process may occur conservatively and swiftly because digital technologies are effortless to reproduce and "inexpensive to scale" (Henfridsson et al., 2014, p. 30). In addition, the inherently intentional incomplete design (Garud et al., 2008) and design flexibility (Henfridsson et al., 2014) afforded by reprogrammability allow ventures to explore and actualize concurrent entrepreneurial opportunities, work on parallel ideas, and even swiftly change ideas when the actualized opportunity does not materialize as expected (Henfridsson et al., 2014; Nasiri et al., 2020). For example, the Internet of things may enable a venture to revisit dynamic data based on improved information processing capability, thereby resulting in more chances of operational agility (Akhtar et al., 2018). Rather than committing to a single resource deployment behavior, new ventures are more likely to simultaneously participate in multiple mindful resource organizing behaviors. This mindful resource organizing resonates well with generativity that promises waves of innovation (Henfridsson et al., 2014) and fosters market-shaping capability (Huang et al., 2017; Nambisan, 2017; Spagnoletti et al., 2021; Yoo et al., 2010). Thereby, it opens up new opportunities to do business in new ways, and significantly changes the outcome of mindful resource organizing even during crisis.

Second-and importantly-digital innovation might potentially expand the scale and scope of mindfulness actors (Nambisan, 2017). Rooted in the convergence of digital innovation, heterogeneous and abundant actors within and across the industrial boundary are flooding into the locus and becoming inter-connected entrepreneurial agencies (Nambisan et al., 2019). Furthermore, catalyzed by reduced information asymmetry and increased transparency among actors (Nambisan et al., 2018), it takes a relatively short time to engage in mindful behaviors. Consequently, collective actors can detect disturbances early, respond quickly, monitor efficiently, and pursue entrepreneurship opportunities collaboratively (Singh et al., 2020; Van Der Vegt et al., 2015). Moreover, the traceability and design flexibility offered by reprogrammability (Henfridsson et al., 2014; Nambisan et al., 2019) enable ventures to monitor activities among partners in real-time, resulting in effective mindful resource management.

Taken together, past literature has placed considerable weight on the anticipation aspect of mindfulness to explain the success that arises from building resilience quickly (DesJardine et al., 2019; Gittell et al., 2006; Parker $\&$ Ameen, 2018). While acknowledging the importance of mindful resource preparation, we argue that the ability to mindfully engage in resource organizing behaviors that enable response to crisis is potentially a far more fundamental solution than previously anticipated. Moreover, the prevalence of digital innovation might disrupt mindful resource organizing, thus considerably shaping the relationship between new ventures and resilience. However, the process by which mindfulness enabled by digital innovation facilitates resilience remains under-explored. To theoretically understand this process, we herein propose the term swift resilience to emphasize how digital innovation facilitates mindful resource organizing that allows for a robust transformation quickly. Swift resilience has become increasingly possible for new ventures, as digital innovation can be used to develop, progress, and support resource organizing behaviors mindfully. Resonating with recent calls to pursue theoretical perspectives of mindfulness (Linnenluecke, 2017; Williams et al., 2017), this paper aims to encapsulate the underlying complex process and develop a more nuanced understanding of mechanisms that afford swift resilience.

\section{Method}

Given the explorative nature of the research question, a qualitative approach drawing on qualitative data was adopted in this study. The case study approach is highly appropriate for the study and research question, where better understanding of this under-researched phenomenon (Drummond et al., 2018) will enrich comprehension and appreciation of the research arena (Beverland \& Lindgreen, 2010). For these reasons, we performed an in-depth, qualitative study of the company Digital ICAR, following state-of-the-art principles for case study research (Goffin et al., 2019).

\subsection{Research Setting}

Digital ICAR offers a suitable setting for our research aims because it offers a revelatory case (Yin, 2009) in which the "paradigmatic of some phenomenon of interest" (Gerring, 2007 , p. 201) is highly represented. The following reasons make the setting particularly appropriate for this study.

First, the venture exemplifies the swift resilience that many other new ventures aspire to, as the venture continuously expanded operations with profitability in $50 \%$ of cities and managed to make a robust transformation-shifting its business model from providing a ride-sharing service to open digital platforms during the COVID-19 pandemic. The venture has been recognized for its swift resilience during the pandemic and its subsequent dedicated efforts regarding co-developing technologies for ongoing risk hedging, receiving awards such as Service Innovative Enterprise, and Outstanding Social Responsibility Award, and a place in The Most Resilient Chinese Enterprises During COVID-19. It has also successfully raised hundreds of millions of RMB in Series B funding since the COVID-19 pandemic started.

Second, our theoretical interest in multiple levels of mindfulness driven by digital innovation is aligned with the 
venture's operation during the crisis. Digital ICAR's swift resilience was facilitated by its mindful resource organizing behaviors afforded by its intelligent hardware, big data, AI, blockchain, and other cutting-edge technologies. Aiming to shift the traditional heavy asset operation mode to a lighter mode, it worked closely with external actors that cover vehicle production's entire life cycle-ranging from production, sales, and aftersales services to second-hand vehicle trading and more. Therefore, the mindful behaviors of this venture continuously surface over time as it expanded its actors, such as manufacturers, distributors, second-hand vehicle agencies, and leasing ventures. Thus, this venture represents an ideal case study by which to capture the dynamic aspects of mindfulness.

\subsection{Data Collection}

To address our research question and triangulate the findings, we combined primary in-depth interview and secondary data sources. In-depth, semi-structured interviews were used for primary data collection. The rationale for adopting the in-depth interview was that it enabled us to address "how" and "why" types of questions (Yin, 2009). Table 2

Table 2 Summary of data sources and use

\begin{tabular}{ll}
\hline Data sources & Type of data \\
\hline Semi-structured interviews & Jan $2020-$ April 2021 (total of 51 interviews, generating \\
& 385 pages of transcription plus 103 pages of notes) \\
People involved in the operations of the venture after & COVID-19 (25 informants; 37 interviews with an \\
& average 60 -min length) \\
$\bullet$ & 30 interviews at headquarters with senior manag- \\
& ers, such as the founder, general manager, operation \\
& manager chief, technology officer, product manag- \\
& ers, marketing director, customer manager, and other \\
& employees \\
$\bullet$ & 7 interviews with managers at the regional level, such \\
& as regional general managers and local after-sales \\
& managers \\
& Key investors, partners, competitors, and customers \\
& of the venture (13 informants; 14 interviews with an \\
& average $60-$ min length) \\
$\bullet$ & 2 interviews with investors \\
$\bullet$ & 5 interviews with partners, such as vehicle manufac- \\
& turers, distributors, and technology companies \\
$\bullet$ & 4 interviews with competitors, such as other vehicle \\
& leasing companies, motorhome companies, etc. \\
$\bullet$ & 2 interviews with key customers \\
&
\end{tabular}

Archival data

Participant observation

Informal dialogue
Jan 2020-May 2021 (total of 863 pages of documents)

- 4 project descriptions

- 40 pages of meeting minutes

- 10 technical specifications

- 30 website pages

- 64 newsletters

- $561 \mathrm{WeChat}$ official accounts (selected)

- 235 Weibo (selected)

- 121 Press releases

Jan 2020-April 2021 in Beijing and Zhejiang (total of 13 occasions, generating 133 pages of notes)

- 4 internal meetings $(5 \mathrm{~h})$

- 2 workshops $(7 \mathrm{~h})$

- 7 social gatherings $(25 \mathrm{~h})$

Jan 2020-April 2021 (total of 124 pages of notes) - Interviews with the founder and the management teams during the field visits

- 11 phone conversations, numerous simultaneous WeChat conversations with general and city managers
Use in the analysis

- Detailed understanding of rationale and strategic intent

- Deeper understanding of the creation of mindful resource organizing behaviors and finding evidence of the enactment of the cause

- Understanding of the nature and connections between mindful organizing behaviors

- Familiarity with the research setting and obtaining contextual information

- Development of historical account of events and their impact over time

- Characterization of historical account of resilience and its impact over time

- Triangulation and integration of the evidence derived from interviews and observations

- Development of historical account of events and their impact over time

- Characterization of cause

- Triangulation and integration of evidence derived from interviews and observations

- Development of historical account of events and their impact over time

- Understanding of the emotional reaction of identification, evidence of enactment

- Characterization of the cause

- Triangulation and integration of evidence derived from interviews and observations 
summarizes the data and their uses. Specifically, we identified key informants within the chosen venture, based on relevant experience and position. Managers were initially approached within the selected venture via e-mail. The founder, senior managers, and employees who had worked before and during the COVID-19 pandemic were approached. We interviewed key informants multiple times to explore the emerging issue. Each one-to-one interview typically lasted $60 \mathrm{~min}$. After the interviews, the venture's partners were contacted and included in the research to fully understand the firm's resilience activities. Each of these semi-structured interviews again lasted an average of $60 \mathrm{~min}$. In total, we conducted 51 interviews, including several runs interview with 15 managers, 10 venture employees, and 13 external informants (including partners, competitors, and customers). In order to record exact words, we took detailed notes during and immediately after each conversation. Permission was granted to record and transcribe 31 interviews (with the help of a professional transcription service), and we took extensive notes for the other 15 , resulting in a total of 385 pages of single-spaced transcription and 103 pages of notes. Moreover, in order to ensure the triangulation and consistency of data, we adopted archival data from official online websites, social media, and so on, as well as participant observations and informal dialogues. The secondary data amounted to 863 pages of relevant releases, reports, and highly detailed specifications for the various technologies involved. These documents allowed us to capture both the original state of Digital ICAR and how it evolved.

\subsection{Data Analysis}

We coded the interview transcriptions to establish common themes emerging from the data. The analysis followed Gibbs's (2002) framework to analyze data-creating open coding, axial coding, and aggregated coding. The data structure is presented in Fig. 1. We adopted an iterative approach to travel back and forth between data, literature, and emerging theory to solicit the themes (Locke, 2001). During Phase 1, we began with a big picture of what the venture has made. From there, we generated the first order (left column of Fig. 1) to identify the empirical codes that were central to the informants during both observations and interviews (Maanen, 1979). We also cross-checked the preliminary case narratives with different sources of data in our set, such as project descriptions, technical documents, and releases on social media, to avoid overreliance on interview data. To ensure the reliability of our understanding of the organization and key focus, two of the authors separately conducted open coding for six months. In Phase 2, known as selective coding, we compared similarities and differences in various first-order codes. We adopted concepts from mindfulness and digital innovation literature as analytical filters to cluster first-order codes in Phase 1. This step enabled us to develop the theoretical concepts involved in the swift resilience process from broader categories of first-order empirical observation as the second orders. As a result (indicated in the middle column of Fig. 1) we identified the context conditions, digital innovation, ongoing actions, and outcomes behind or related to swift resilience. We also developed Tables 3, 4, 5, 6, 7 and 8 to articulate how the first-order empirical observations related to the second theoretical concepts. In Phase 3, by conducting selective coding (Strauss \& Corbin, 1998), we aimed to identify the relationships between different second-order codes and distilled them to aggregated dimensions (right-hand column of Fig. 1) by which the venture achieved swift resilience. Drawing on the notions of organizational resilience, mindfulness, and digital innovation, we unpacked the interrelationship among the aggregated dimensions that were identified during the three steps. We then refined categories and themes into a process model of swift resilience (Fig. 2) that accounted for changes in the mindful resource organizing behaviors. Subsequently, we reached an agreement among the authorship team after the iterative process of revisiting the transcript, the existing theory, and our research question.

\section{Swift Resilience: Contextual Conditions, Mechanisms, and Outcomes}

\subsection{Contextual Conditions of Swift Resilience}

As indicated in Table 3, we observed two contextual conditions that facilitate venture extension: prosocial motivation and entrepreneurial opportunity. First, prosocial motivation refers to a prosocial mindset that promotes a venture proactively aiding others in need. After identifying the pain points in the industry, the managerial team realized that the venture could sustain its resilience only if they devoted efforts to industrial resilience. The contextual condition of entrepreneurial opportunity captures the emerging opportunities of sensing and seeking (in this case largely carried out by the managerial team).

These two contextual conditions can be found in the way they trigger swift resilience. Specifically, the venture's prosocial motivation rationalizes following cooperative actions with external actors. The entrepreneurial opportunity represents its cognitive capacity in actualizing opportunities into some commercial reality. It is worth noting that achieving organizational resilience is far from enough; the venture is expected to consider industry resilience as a whole during the COVID-19 crisis.

Despite the importance of the two contextual conditions, they do not represent the actual actions and processes of carrying out swift resilience. The three distinct yet interconnected 
Fig. 1 Data structure

\begin{tabular}{|c|c|c|}
\hline First-order Codes & Second-order Codes & Aggregate Theoretical \\
\hline $\begin{array}{l}\text { - Industrial problems during COVID-19 } \\
\text { - Prosocial mindset }\end{array}$ & $\rightarrow$ Prosocial motivation & nsion \\
\hline $\begin{array}{l}\text { - Opportunity sensing } \\
\text { - Opportunity seeking }\end{array}$ & $\rightarrow \begin{array}{l}\text { Entrepreneurial } \\
\text { opportunity }\end{array}$ & ondition \\
\hline $\begin{array}{l}\text { - Anticipation based on existing user data } \\
\text { - Evaluation of emerging situations through machine learning }\end{array}$ & $\rightarrow$ Prediction & \\
\hline $\begin{array}{l}\text { - Automatic risk monitoring } \\
\text { - Autonomous decision making }\end{array}$ & $\rightarrow$ Automation & Digital \\
\hline $\begin{array}{l}\text { - Connection with external actors } \\
\text { - Traceability among actors }\end{array}$ & $\rightarrow$ Relationality & \\
\hline $\begin{array}{l}\text { - Immediate restructuring operation facilitated by business } \\
\text { intelligence systems, and predictive and analytic algorithms } \\
\text { - Rapid adding of necessary processes } \\
\text { - Quick outsourcing of some local operations } \\
\text { - Swift role shifting }\end{array}$ & $\begin{array}{l}\text { Quick rehabituating with } \\
\text { digital resources at hand }\end{array}$ & h \\
\hline $\begin{array}{l}\text { - Quick launching of a variety of whole rental products and } \\
\text { replicating of existing offerings geographically } \\
\text { - Relentless upgrading of operations afforded by real-time self- } \\
\text { reinforced algorithms and feedback from employees and } \\
\text { external actors }\end{array}$ & $\begin{array}{l}\text { Continuous expanding } \\
\text { and improvising with } \\
\text { real-time monitoring }\end{array}$ & \\
\hline $\begin{array}{l}\text { - Establishing a co-competition relationship with competitors } \\
\text { - Quick granting of application access to actors across the } \\
\text { industry } \\
\text { - Temporal borrowing of labors outside in a gig economy }\end{array}$ & $\rightarrow \begin{array}{l}\text { Instant mobilizing of } \\
\text { external resources }\end{array}$ & \\
\hline $\begin{array}{l}\text { - Selective cooperating with competitors that are } \\
\text { geographically and categorically hard to reach } \\
\text { - Partial sharing with competitors } \\
\text { - Monitoring numerous actors with a central control } \\
\text { - Offering partners the flexibility of multi-homing }\end{array}$ & $\begin{array}{l}\text { Dynamic controlling of a } \\
\text { number of heterogeneous } \\
\text { resource exchange } \\
\text { activities }\end{array}$ & Sharing \\
\hline $\begin{array}{l}\text { - Quick carrying out of its trusteeship scheme toward external } \\
\text { actors } \\
\text { - Launching a business close loop through down-side and up- } \\
\text { side supply chain integration } \\
\text { - Proposal of a crowdsourcing scheme for after-sales vehicle } \\
\text { service }\end{array}$ & $\rightarrow \begin{array}{l}\text { Proactive templating of } \\
\text { concurrent ideas around } \\
\text { the core business }\end{array}$ & \\
\hline $\begin{array}{l}\text { - Quick divesting of the operations in some cities when the } \\
\text { cities are not profitable } \\
\text { - Instant narrowing down of the crowdsourcing scheme in } \\
\text { terms of C-side customers } \\
\text { - Canceling of trusteeship for individuals that prove unviable }\end{array}$ & $\begin{array}{l}\text { Immediate withdrawal of } \\
\text { non-successful trials }\end{array}$ & Pivoting \\
\hline $\begin{array}{l}\text { - Repositioning itself as a technology company that focuses } \\
\text { on platform ecosystem construction } \\
\text { - Separating the vehicle after-sales service from its business }\end{array}$ & $\rightarrow \begin{array}{l}\text { Quick transforming to a } \\
\text { new equilibrium }\end{array}$ & \\
\hline $\begin{array}{l}\text { - Continuous attracting of actors through network effects } \\
\text { - Fostering of technological knowledge diffusion and risk } \\
\text { hedge within and across the industry in the long run } \\
\text { - Constructing collective identification via gaining support } \\
\text { from the local and national governments }\end{array}$ & $\rightarrow \begin{array}{l}\text { Continuous sustaining of } \\
\text { the new equilibrium }\end{array}$ & \\
\hline
\end{tabular}

mechanisms enabled by digital innovation are essential in understanding such dynamics, which are depicted in Table 3.

\subsection{Digital Innovation}

The heart of Digital ICAR's business is its digital capabilities, catalyzed by its digital innovation. These capabilities work as a foundation for the three mechanisms of swift resilience. As elaborated in Table 4, digital innovation consists of three conceptual themes: prediction, relationality, and automation. First, the conceptual theme of prediction makes the venture enhance operational effectiveness. Our data analysis indicated that the prediction afforded by digital technologies played a pivotal role at the initial stage of the crisis. Serving as a basis for the consideration of which opportunity to seize, prediction makes the venture balance reusing of the existing operation with continuing to mindfully improvise. Moreover, our case showed that the venture could align with external actors due to the second conceptual theme, relationality. Digital infrastructures, such 
Fig. 2 A Process Model of Digital Innovation Enabled Mindfulness for Swift Resilience

\begin{tabular}{|c|c|}
\hline \multicolumn{2}{|c|}{ Figure 2: A Process Model of Digital Innovation Enabled Mindfulness for Swift Resilience } \\
\hline Conceptual Categories & Definitions \\
\hline \multicolumn{2}{|r|}{ Contextual Conditions } \\
\hline Prosocial motivation & $\begin{array}{l}\text { A prosocial mindset that facilitates ventures to proactively } \\
\text { aid others in need }\end{array}$ \\
\hline $\begin{array}{l}\text { Entrepreneurial } \\
\text { opportunity }\end{array}$ & Proactive sense and desire to seek emerging opportunities \\
\hline \multicolumn{2}{|r|}{ Digital Innovation Enabled Mindfulness } \\
\hline Digital innovation & $\begin{array}{l}\text { The recombination of digital components in a layered, } \\
\text { modular architecture }\end{array}$ \\
\hline $\begin{array}{l}\text { Digital-driven } \\
\text { stretching }\end{array}$ & $\begin{array}{l}\text { The process by which a venture instantly restructures and } \\
\text { redeploys available resources at hand to fit with the new } \\
\text { conditions with marginal cost }\end{array}$ \\
\hline Collective sharing & $\begin{array}{l}\text { The process by which a venture openly fosters } \\
\text { interdependent relationships with external stakeholders } \\
\text { within and across industries }\end{array}$ \\
\hline Rapid pivoting & $\begin{array}{l}\text { The process by which a venture alertly monitors external } \\
\text { environments and minimizes the time gap between } \\
\text { opportunity identification and action actualization }\end{array}$ \\
\hline \multicolumn{2}{|r|}{ Outcome } \\
\hline Swift resilience & $\begin{array}{l}\text { Building a new and better equilibrium quickly through } \\
\text { digital innovation enabled mindful resource organizing } \\
\text { behaviors }\end{array}$ \\
\hline
\end{tabular}

as T-box, BI systems, and invented applications, could be quickly integrated to external actors, such as partners and competitors, within and across the industry. Contributed to by digital innovation, the empirical observation showed that the venture was more likely to synthesize distributed stakeholders into a coherent whole after the crisis because industrial boundaries became more blurred. Also, the automation caused the venture to not only monitor emerging dangers but also to enhance efficiency by adopting effortless and autonomous decision-making. Therefore, the venture was more likely to simultaneously take part in multiple trials and errors. We noted that prediction, relationality, and automation afforded by digital innovation were incorporated into all episodes of the swift resilience process and support mechanisms of mindfulness.

\subsection{Swift Resilience Mechanism: Data-driven Stretching}

We use the term data-driven stretching to represent the process by which the venture mindfully reuses existing resources at hand, responding to ever-changing environments. Specifically, this mechanism consists of a complex set of internal activities for reconfiguring and redeploying 
Table 3 Contextual conditions

First-order analysis and illustrative evidence

- Industrial problems during COVID-19

The traditional vehicle-sharing industry has faced three significant challenges: heavy assets, heavy operations, and limited sources of making money. Specifically, most enterprises are overwhelmed by heavy asset investment during the pandemic, in particular, engine factories and dealers with heavy inventory struggling with an imbalance between production and sales. (The release)

For vehicle-sharing enterprises, how to be profitable is essential. They need to solve vehicle scheduling, refueling and charging, and other operational problems. The cost for engaging in this operation is high, while the profit is solely from the renting fee. (The industrial expertise)

- Prosocial mindset

"It is a challenging period for the whole industry. Manufacturers, dealers, and vehicle renting ventures, etc., we all suffer from severe losses. Simply reestablishing our operation is far from enough. We have to take the whole industry and society into consideration. We could ultimately embrace resilience, but not until the entire industry recovers from the pandemic. Therefore, we always try to do something that benefits other actors in the industry as well." (The founder)
- Opportunity sensing

"Previously, we mainly focused on offline consumption. Thanks to the COVID-19 pandemic, consumers changed their consumption patterns quite a lot, such as viewing vehicles online, door-to-door test driving, door-to-door maintenance, etc. It is potentially a good chance for us. We believe our technologies could facilitate us to seize the opportunity quickly." (General manager)

- Opportunity seeking

"We believe the pandemic is an opportunity for us. If you work solely in a timesharing business, you will not be able to survive. Since car-sharing is naturally close to users, we could take this advantage to break through the information asymmetry in the industry. The accumulated data will facilitate us to strive to make a difference in the next stage." (The founder)
Second-order analysis

Prosocial motivation

Aggregate theoretical dimension

Initial Condition resources at hand for new uses. As summarized in Table 5, three underlying conceptual themes explain how the mechanism of data-driven stretching works.

First, we noted that Digital ICAR was able to quickly rehabituate with digital resources at hand despite the disturbances caused by the COVID-19 pandemic. Thanks to the versatile BI systems, and predictive and analytic algorithms, the venture was capable of restructuring operation planning, adding operation procedures, and outsourcing business operations in a swift manner with relatively marginal costs. In responding to operational adjustments, the internal role shift was also quickly arranged. For instance, a new department was rapidly established to provide managerial guidance to outsourced city partners. Although this department was unfamiliar with numerous city situations, the onecity-one-plan scheme was executed smoothly, following a hybrid model of human and autonomous decision making. The venture also mindfully decentralized the decision making to regional city managers, since the centralized decision making was inefficient due to hectic and chaotic conditions. In addition, in order to enhance internal responsiveness, the systems and algorithms decided various operational labor adjustments, such as disinfection staff.
Given the ever-changing disturbances, we use the second conceptual theme of continuously expanding and improvising with real-time monitoring to capture the mindful activities in the long run, specifically with its significance for quickly reusing existing routines for potential opportunities. We observed this among case informants as they reflected on how the venture rapidly seized the emergent consumption trend through both service offering categories and Digital ICAR's geographical expansion. When the venture mindfully reused its existing resources to expand the business, we noted that it explicitly monitored the operation and continuously adjusted according to self-reinforcement and feedback, with a close eye on emerging opportunities.

\subsection{Swift Resilience Mechanism: Collective Sharing}

Our analysis showed a significant capability within Digital ICAR to collectively exchange resources with various heterogeneous actors. We refer to this mechanism as collective sharing (Table 6). Given the initial resources for the new venture, it engaged in unavoidable leveraging of mindful resource development and exchange behavior with external actors. 
Table 4 Digital innovation

- Anticipation based on existing user data

"We have installed intelligent terminals such as T-box, service recorder, etc., in each vehicle to achieve real-time visibility of vehicle conditions, vehicle position, driver risk behavior, and the conditions inside and outside the vehicle. According to the analytic of our BI system report and analytical algorithms, we can immediately identify and analyze customers' real-time and historical driving routes, temporary parking of vehicles, parking thermal maps, user thermal maps, etc. Hence, we could quickly adjust our operation, such as available vehicles according to matching, recommendation, and prediction algorithms." (Data scientist)

- Evaluation of emerging situations through machine learning

"Often, we don't have the specific data to predict some new businesses like those operating in new cities. Therefore, we will use machine learning to learn users' [historic] consumption habits and distill parameters like the shopping mall, train station, etc., then modeling the operations in new cities to improve the predictability. By doing that, we could critically evaluate emerging risks and opportunities." (Product technology developer)

- Connection with external actors

"We have invented some integrative systems that are able to connect to our BI systems, inventory systems, and decision-making systems, among others. Also, we try to grant specific access to our partners and help them to connect their operating systems to our systems; thus, helping them monitor their renting vehicles in real-time." (Chief Technology Officer)

- Traceability among actors

"The entire operation process is pretty transparent as we have effectively integrated intelligent hardware with our invested systems and algorithms. For instance, we have used blockchain to enhance the transparency among partners." (Operation manager)

\section{- Automatic risk monitoring}

"Our algorithms monitor and automatically offer earlier warnings of abnormal behaviors, such as non-driving, fatigue driving, drunk driving, and smoking in the vehicle. Thus, we can diminish vehicle accident rates with effective fraud detection. When the system detects that the driver is over the alcohol limit, the T-box will refuse to send driving instructions. The same situation applies to vehicle collisions, abnormal vehicle moving, vehicle battery loss, etc. In addition, the whole vehicle service processes, such as maintenance and cleaning, would be recorded, thus facilitating the transparent information flowing over the entire process." (Risk technology specialist)

- Autonomous decision making

"To deal with the chaotic situation after the COVID-19 pandemic, we must upgrade the decision models [from BI and big data to machine learning]. Autonomous decision-making at the operational level significantly accelerates the efficiency during the operation. It can effectively release our employees to do more innovative trial and errors." (Team leader in technological department)
Prediction

Digital Innovation
Relationality

Automation
First, the theme of instant mobilizing of external resources without ownership captures the activities that a venture leverages on a large number of heterogeneous resources to fulfill its purposes. For a venture that would like to be resilient quickly during and after a hardship such as the pandemic, achieving resilience at the organizational level is no longer enough, as indicated in the case. Research showed that mobilizing external actors' specificities and achieving resilience through helping others were far more sustainable solutions. Such learning was particularly crucial for the venture; therefore, the venture mindfully built a co-competition relationship with numerous competitors, leveraged specificity from actors across the industrial boundary, and borrowed slack labors from partners and the public. A large number of heterogeneous resources could be quickly assembled when digital innovation was at the core.

After they build interdependency with these actors, how to dynamically manage the relationship is essential. The second theme, dynamic controlling of a number of heterogeneous resource exchange activities, refers to mindful control with flexibility. Digital ICAR selectively cooperated with competitors in a specific service category, such as motorhome leasing, and competed with them in other leasing business. It also mindfully separated the cooperation and competition according to the geographical locations. In addition, the venture partially shared operational and market 
Table 5 Data-driven stretching

- Immediate restructuring operation facilitated by business intelligence systems, and predictive and analytic algorithms

"According to a configuration plan made by the automatically designed schedule, we have resumed our operations specifically for each city." (The founder)

"Although our orders have not reached the previous level, our business has gradually recovered with the work resumption. Moreover, the operation situation and user distribution have changed significantly. For instance, the consumption used to be multi-scene, such as commuting and leisure places. Now it's all about commuting We can quickly reoptimize vehicle scheduling and adjust the number and layout of vehicle stopping points appropriately through the BI systems, and predictive and analytic algorithms." (Operation manager)

- Rapid adding of necessary processes

"Afforded by the traceability and real-time visibility of customer information like the vehicle driving roadmap and parking history, we are able to generate vehicle usage reports immediately. Therefore, we can quickly add the 'contactless pickup and return' for the whole renting service in order to comply with social distancing during the pandemic period. Customers can easily place an order through the rental page of our app. The rental specialist of our platform will contact the user and guide him or her to complete the vehicle inspection at the designated branch virtually. Then they could use the rented vehicles speedily. Also, our customers are free to return the vehicle at the designated vehicle outlets without human contact." (General manager)

"We also dynamically adjust labor to do the disinfection following the guideline of systems. Thanks to the automated suggestion, we can do specific infections mindfully. For instance, for sharing vehicles, we would deep clean right after the completion of each service. We would provide a disinfection service to daily and monthly rental customers right before customers pick the vehicle up and return the vehicle, respectively. Factors like vehicle locations and labor distributions are put into the systems, and the working schedules are generated automatically and quickly. We just follow the plans." (City manager)

- Quick outsourcing of some local operations

"To further reduce our cost, we have implemented city partners' schemes in selected cities to outsource operations to other agencies. We grant these competitors access to our BI system and provide localized managerial suggestions to city partners. This mode has effectively eased the industry problem of 'heavy operation and heavy assets' and achieved a win-win situation between the venture and franchised enterprises. We have monetized our technological service to agencies who have slack vehicles." (General manager)

- Swift role shifting

"A new department was quickly fostered to focus mainly on the city partner scheme. Although the new department members are previously from various departments, facilitated by hybrid autonomous and human decision-making, the team can quickly develop a specific city management plan that fits with the city's situation. They could quickly make detailed operation plans, including team building, layout planning, vehicle selection, professional technical support, and a transparent profit model." (Human resource manager)

"To deal with the chaotic situation after the COVID-19 pandemic, we must upgrade the decision models [from $\mathrm{BI}$ and big data to machine learning]. Also, since we delegate operation decision rights to local general managers, the updated decision-making model may facilitate these managers to maintain responsiveness in real-time. Despite the lack of specific expertise guidelines, the general manager can make a quicker operational decision with the assistance of these models. At the same time, senior managers in the headquarters are capable of mindfully and remotely monitoring localized operations via revisiting our decision-making systems." (The founder)

- Quick launching of a variety of whole rental products and replicating of existing offerings geographically "Since the pandemic, customers have new travel demands-personal and safe travel. Safety has become one of the primary considerations of travel trips. The most straightforward solution to the safety issue is to buy a vehicle. However, license plate restrictions in first-tier cities and the high cost of purchasing and holding a vehicle in second-tier and third-tier cities suppress consumers' desire to buy a vehicle. An alternative way is to use someone else's vehicle. During COVID-19, customers tended to choose safer, more private, and more controllable personalized travel. Therefore, this gave us a great opportunity." (The founder)

The venture has quickly diversified existing renting services through integrating existing ride-sharing systems with multiple customized vehicle rental offerings. For instance, to meet the differentiated travel needs of customers, the venture has launched the discount scheme for the whole rent and daily rent with more flexible seven- and 15-day rental packages. Based on the expansion plans made by the prediction algorithm, it has also rapidly seized new opportunities to expand the business to third-tier and fourth-tier cities. It is reported that since the resumption of work, the ventures' travel rental and daily rental business nearly doubled. (The release) - Relentless upgrading of operations catalyzed by self-reinforced algorithms and feedback from employees and external actors

"We are able to immediately revisit our users' vehicle leasing information, such as the movement of vehicles in each area, daily transaction volume, and so on. The system could grasp the vehicle's situation in real-time through the algorithm, thus optimizing the overall scheduling with reduced operating costs. We update the systems to optimize the operation process effectively and efficiently. Also, we frequently revise service offerings with the assistance of employees' and customers' feedback. With intelligent hardware, artificial intelligence, blockchain, and other technologies, we can monitor operation difficulties and enhance customer experience via immediate after-sales services." (Technological manager)

"Thanks to our customer resources, predictive algorithms, and machine learning, we could continuously devote efforts to business model innovation and user experience improvement." (The founder)
Quick rehabituating with digital Data-driven Stretching resources at hands

Continuous expanding and improvising with real-time monitoring 
Table 6 Collective Sharing

- Establishing a co-competition relationship with competitors

"Indeed, our competitors are ourselves. We are in a race against time. Competitors are more friends than rivals. If anyone [competitors] wants to cooperate with us, we would like to find a way to cooperate with them. Thereafter, we could get initial access to each other's customers." (The founder)

"We have established cooperative relationships with some leasing agencies quickly since they can trace details about operational details, transactions, and customer information in a realtime manner. We can forge swift guanxi immediately." (Operation manager)

- Quick granting of application access to actors across the industry

"To pursue expansion, we also grant a number of travel agencies access to our application. Relevant travel recommendations will be integrated into our application. We call it 'daoliu'-enabling external actors to reach our customers. On the one hand, we could effectively expand our application's scope without necessarily knowing how to operate them. On the other hand, our partners will benefit from our customer base. It's a win-win deal, and it is not a very complex task at the operational level." (Product manager)

The venture engages in "lightweight" transformation by bridging a direct transaction between partners with customers. Its business is no longer limited to the car-sharing business unit. (The release)

- Temporal borrowing of labors outside in a gig economy

"We have worked with Diane - the company in labor management—-to temporarily utilize their labors during the COVID-19 pandemic. Moreover, we have assigned temporarily flexible employment contracts with our partners. We are committed to adjusting our labors for emergency use. We have also absorbed part-time labor in public to work on our after-sales service business. Building upon operational management and schedule management systems, we could quickly match labor force demands of [our company] with available laborers [part-time labor borrowed from other partners like Kuai Car who has slack staff temporarily; casual labor during COVID-19]. Since the operations are mainly data-driven, newly borrowed laborers are familiar with our process within a short period." (Human resource manager)

The crowdsourcing services mean a two-way activation where users are both consumers and employees; thereafter, users benefit from marginal revenue and increase the users' stickiness to the application. The venture creatively increases the stickiness by enhancing the interactions. (The release)

- Selective cooperating with competitors that are geographically and categorically hard to reach

"We selectively cooperate with competitors in the areas that we find hard to reach. First, we tend to cooperate with our competitors for the cities that we do not currently cover. We grant them access to the application. Second, we would like to partner with competitors who focus on other product categories, such as motorhome sharing companies, to enrich our product offering. For instance, customers in Guiyang province can enjoy a daily rental discount for motorhome vehicles if they place an order in our application." (General manager)

- Partial sharing information with competitors

"With the visibility and traceability afforded by the blockchain, we offer our competitors the key partner account, provide partial data access such as their customers' information and share general industrial insights with them. Also, the blockchain - the decentralized ledger in the network-allows for safe financial transactions between two or more actors involved in networks. Moreover, we keep actors updated with requirements and specifications as the feedback evolves." (Technological staff)

- Monitor numerous actors with a central control

"Meanwhile, we are able to realize a real-time monitor of external operations in our application. The [information of] transactions could quickly be assessed. Moreover, there is an alarm made by the algorithms if customers are abnormal." (General manager)

- Offering partners the flexibility of multi-homing

"The transparent information flow in the application, such as the ever-changing prices of services available in the platform, grants the partners the freedom to cooperate and compete with the venture mindfully. The partners are free to offer services in various applications. They have the freedom to switch among their platform, our competitors' platform, and our platform. We are okay with it. Consequently, we have forged a flexible relationship with our partners." (Product manager)
Instant mobilizing of

Collective Sharing external resources

without ownership
Dynamic controlling of a number of heterogeneous resource exchange activities 
resources through digital resources such as blockchain and analytic algorithms. At the same time, it offered flexibility for partners to be multi-homing-providing services in various applications. Partners were free to serve multiple platforms, despite the cooperative relationship built with Digital ICAR.

\subsection{Swift Resilience Mechanism: Rapid Pivoting}

Our case analysis indicates that Digital ICAR should engage in a series of changes in terms of strategies. We refer to this mechanism as rapid pivoting, which denotes a venture's openness to strategic addition and exit strategies.

As shown in Table 7, our analysis yielded two conceptual themes related to rapid pivoting. First, the venture proactively templated concurrent ideas around core business, such as a trusteeship scheme, service innovation, and crowdsourcing, to concurrently integrate the supply chain's downside and upside. Even though the venture could engage in numerous templating in parallel, such as trusteeship, supply chain integration, and crowdsourcing schemes, they always worked around their core business, and a significant degree of pivoting was not allowed. Concentrated templating was therefore considered important. The second conceptual theme was immediate withdrawal of non-successful trials. Not all attempts were successful. Thus, the venture was engaging in an ongoing cutting-off process with alertness, although some cut-downs were a relatively small portion of the plan. For instance, quick shifting from the city partner model back to self-operated business created instant narrowing down of the crowdsourcing and trusteeship schemes. The digital systems and analytic algorithms enabled Digital ICAR to abandon unsuccessful activities with relatively marginal efforts.

\subsection{The Outcome of Swift Resilience}

Regarded as one of the outstanding resilient Chinese enterprises during COVID-19, we noted that Digital ICAR quickly transformed to a new equilibrium, that is, officially launched its platform to provide integrated technology service for time-sharing business and vehicle service management (Table 8 ). The venture successfully achieved profitability through a quick recovery of its user base and ultimately realized its transformation-becoming a technical service provider. Also, it continuously sustained its new equilibrium through attracting participants in its platform ecosystem and mindfully taking responsibility to cooperate with technological ventures for risk hedge in the long run. It tended to further grow the platform ecosystem via gaining legitimacy of its new image from governments, the release, and various investors.

\section{Discussion}

The starting point for this research is that digital ventures achieve resilience quickly. Problematizing the current literature (Powley, 2009; Ramezani \& Camarinha-Matos, 2020; Weick \& Sutcliffe, 2007), we observe that the conventional assumption of mindful resource preparation in extant literature cannot fully address the swift resilience issue. In fact, digital innovation with its unique characteristics (Henfridsson et al., 2014; Huang et al., 2017; Yoo et al., 2012) offers the potential to repurpose mindful resource organizing behaviors such as quick digital resource deployment and dramatic external resource mobilization. A recent study also pointed out the shifting of mindful preparedness to mindful organizing for resilience (Williams et al., 2017). Therefore, we explore mindful resource organizing driven by digital innovation as a powerful path to swift resilience, building on the anecdotal observation that this is increasingly important as new ventures work to thrive during the COVID-19 crisis.

\subsection{A Process Model of Swift Resilience}

We offer a new process model that documents and conceptualizes swift resilience through a case study. Figure 2 depicts the process model developed from our data analysis. The model consists of (a) the contextual conditions that trigger the process, (b) the mechanisms by which digital innovation interacts with mindful resource organizing behaviors, and (c) swift resilience outcome.

The model explains that entrepreneurial opportunity and prosocial motivation are necessary initial conditions for building resilience quickly. We refer to prosocial motivation as a prosocial mindset that facilitates ventures to proactively aid others in need. Such an attitude is an essential condition that achieves its resilience via helping others. Moreover, another contextual condition is entrepreneurial opportunity, which refers to a venture's sensitivity to emerging opportunities and its choice to proactively seek opportunities. With the entrepreneurial opportunity in place, a venture is more likely to seize opportunities later on, facilitated by digital technologies at hand.

The two contextual conditions are crucial catalysts for triggering the mechanisms of swift resilience. Digital innovation, a layered and modular architecture with analytics, relationality, and automation, works as a foundation that enables mindfulness with three mechanisms. To begin, a venture initially engages in data-driven stretching quickly, which denotes a tactical approach that focuses on instant restructuring and redeploying of available resources at hand to fit with new conditions, all at a relatively marginal cost. Our study echoes the call of how mindfulness can be embodied in routines (Vogus \& Sutcliffe, 2012) by explaining swift 
Table 7 Rapid pivoting

- Quick carrying out of its trusteeship scheme toward external actors

"The COVID-19 pandemic hinders the public's demand for going out. Due to the pandemic, the inventory warning index of manufacturers and dealers has risen to $80 \%$. At the same time, this creates an opportunity for us. Before the pandemic, manufacturers and dealers focused more on selling vehicles directly to customers and reluctantly cooperated with us. During and after lockdown, manufacturers and distributors have changed their minds and are more willing to participate in our suggested schemes due to the ever-increasing idle vehicle. We then seized the opportunity and quickly templated a few ideas around the automobile industry. For instance, thanks to the revisability of vehicle-using situations afforded by digital technologies, we can promptly attract wholesalers, vehicle manufacturing factories, second-hand vehicle ventures, and other players in our trusteeship scheme. The trusteeship scheme can be interpreted as partner companies entrusting spare vehicles to us, and we share profits following the agreed proportion. Embedded with our asset management capabilities, we try to tackle the pain point in the industry - heavy assets - and create more value for vehicle companies, dealers, and vehicle rental users. We have currently worked with more than 10 dealers, and most of them have already been profitable." (The founder)

- Launching a business close-loop through downside and upside supply chain integration

To ease the burden of heavy asset investment of vehicles and revitalize vehicle inventory, the venture creates a "onestop exposure + deep experience new vehicle sales model" for manufacturers and distributors. The venture has promoted the innovative operation mode of "personalized travel service + professional vehicle operation system + auto assets revitalization," encouraging partners in the auto industry chain to join their network SaaS platform. Therefore, on the one hand, the distributors can enrich their customer base and improve operational efficiency. On the other hand, the factory can fully revitalize vehicle inventory and get more accurate customer feedback directly for precision production. As a result, it builds a closed business loop from research and development, manufacturing, and customer consumption. (The release)

"Built upon the user data, operational capabilities, and resource integration capabilities, the venture proactively expands to a vehicle selling business through offering customized renting and purchasing packaging. The venture's test drive mode is different from the traditional test drive mode. Users can get access to the new vehicle models earlier. Also, there is no need for a point-to-point test drive on a fixed line. Customers can choose the route freely and use it several times. It has enhanced the connection between new vehicles and potential vehicle buyers. The Test Drive, launched by Volkswagen and us, is one of the most successful trials." (Marketing manager)

"The in-depth test drives enable us to experience a full range of vehicle performance; then, we can find out which vehicle is more suitable." (One of the customers who signed up for the Test Drive program)

"We also cooperate with the manufacturers to introduce a "travel package" at the stage of vehicle purchase that allows owners to offset the cost of vehicle purchase by joining trusteeship. For instance, customers can purchase the usage right from the manufacturer. When a new model comes out, customers can also negotiate to replace it with the new model." (Sales manager)

- Proposal of a crowdsourcing scheme for after-sales vehicle service

The mode of "vehicle service crowdsourcing," a new trial in the gig economy, aims to transform industry development using an Internet mindset. It tries to make full use of the idle labor force in society and effectively increase efficiency with the lowest cost. (The release)

"Crowdsourced services aim to provide a series of after-sales services such as pickup and maintenance, vehicle flash delivery, vehicle washing services, used vehicle evaluation, etc. Owners can quickly connect and match with errands, flash delivery, vehicle washes, and other services through the vehicle service system, resulting in a comprehensive closed-loop between people, vehicles, and scenes. As a result, after one month of crowdsourced services, the vehicle's maintenance cost decreases roughly by $10 \%$, and the timeliness increases by $51 \%$." (Operation manager)

- Quick divesting of the operations in some cities when the cities are not profitable

"Later on, we have no choice but to close down businesses in some cities that are unviable. The reason is complicated; government policy, partners' inability, the uneducated market, competitors, etc. Additionally, we might also change some partnership models back to the self-running model. The essential thing is that we can make a quick decision according to the reports generated rapidly by the background system, thus decreasing the loss as much as we can. For instance, we could make a quick adjustment in terms of our employees' work positions and job locations." (Human resource manager)

- Instant narrowing down of the crowdsourcing scheme in terms of C-side customers

"Afforded by the optimized system, we have made a trial to absorb people in public to deliver a vehicle-related service. Customers can use their spare time to make money by completing tasks such as vehicle cleaning and designated location scheduling. However, this business model was not very successful when we tested it in Beijing. Therefore, we immediately cancelled the promotion scheme and only provide this function specifically to our existing customers." (Product manager)

- Canceling of trusteeship for individuals that prove unviable

"In China, there are more than 200 million private vehicles. On average, each vehicle is used for only two hours a day, and more than $90 \%$ of the time is idle. Therefore, we have promoted the 'personal vehicle renting' business as a sustainable business campaign. The model is to expand public vehicle sharing into the private vehicles sector." (The founder)

"However, we have had to withdraw the specific offerings to the public after several meetings with city managers. The idea is good, but the market is not ready. Hence, we only keep this option for our existing customers as a continuous test. We may try to open it to the public later when our figure [report generated by the systems and algorithms] recommends us to do it." (General manager)
Proactive templating of concurrent ideas around core

Rapid Pivoting business

Immediate withdrawal of nonsuccessful trials 
Table 8 The Outcome of Swift Resilience

- Repositioning itself as a technology company that focuses on platform ecosystem construction

Thanks to a quick recovery of its user base and rapid market responsiveness, the venture has successfully achieved profitability and be rewarded as one of the most resilient Chinese enterprises during COVID-19. The venture has officially launched its technology platform to provide integrated technology service for the time-sharing business and vehicle service management. (The release)

- Separating the vehicle after-sales service from its business

"We have separated our after-sales business from our core business. Based on the Internet of things, AI images, video algorithms, strong quality control management, etc., we effectively offer a series of after-sales services such as personal vehicle sharing, vehicle flash delivery errands, and used vehicle evaluation subscriptions." (General manager)

- Continuous attracting of actors through the network effects

The platform, characterized as open and flexible, has continuously attracted positive responses from actors, such as manufacturers, dealers, second-hand vehicle agencies, renting ventures, and travel ventures from Changchun, Tianjin, Shanghai, and others. These actors have entered the platform ecosystem for various reasons, such as idle vehicle revitalization and industrial network accumulation. (The release)

- Fostering of technological knowledge diffusion and risk hedge within and across the industry in the long run

The venture realizes risk hedging via co-developing the technologies with other technology companies and promoting technology exporting to other actors in the ecosystem. In particular, the venture has cooperated with a partner in terms of marketing activities, financial service products, risk control, and security management. In addition, it further strengthens the cooperation depth and service capability in the travel market and provides far more convenient and high-quality service and consumption experiences for both sides. (The release)

- Constructing collective identification via gaining support from the local and national governments

"Since we do not simply decide the identity change, we should take a whole array of stakeholders, such as local government, the technology companies, media, user community, our investors, into consideration. You have to work on it [identify change] with them together. For example, we have engaged the user community in our future plans at the beginning. Listen to these users' voices and suggestions, and proactively update our directions." (The founder)

The venture has been selected as an "Innovative Enterprise in Operation and Service Mode" and won the "Outstanding Social Responsibility Award" for its excellent performance in protecting safe travel during the pandemic. It also received the award "Significant Contribution Through a Digital Transformation During COVID-19," launched by a series of media. (The release)

The venture has continuously raised hundreds of millions of RMB in Series B funding. The investors include the local government industry fund, the state development and investment corporation department fund, etc. (The release)
Quick transforming to a new equilibrium

Swift Resilience

Continuous sustaining of

the new equilibrium existing routine improvisation in a relatively effortless and costless fashion. As reflected in the case, the reprogrammability characteristic of digital innovation affords new ventures the ability to quickly restructure their routines by customizing specific processes, adding various modules of tasks, and outsourcing operations with marginal costs. In addition, unlike prior scholarly work demonstrating mindfulness and involving a broad spectrum of experts as necessary for generating immediate and flexible responses (Carlo et al., 2012; Salovaara et al., 2019), our case shows that effortless lower-level lateral responsiveness is also feasible, afforded by digital innovation. Moreover, with a hybrid of autonomous and human decision-making, multiple data can be mindfully stretched for new use. As such, ventures could absorb these disturbances quickly and keep the stretching momentum continuous by minimizing the cognitive decision bias and learning curve.

The second dimension, collective sharing, refers to the process by which a venture openly fosters interdependent relationships with external stakeholders via the joining of mindful resource behaviors of actors within and across industries. Enabled by the convergence of digital innovation 
(Yoo et al., 2012), a digital venture significantly extends the scope and scale of actors engaged in mindful organizing. Prior studies have primarily emphasized that organizational resilience is affected by mindfully managing internal relations (Kahn et al., 2018; Stoverink et al., 2020). While an initial attempt was made on how to mindfully manage external suppliers' relationships (Zafari et al., 2020), these relationships are more likely to be bilateral in the context of lower network diversity. This empirical evidence supplements the existing literature by delineating how networkbased external mindfulness happens across the industry boundary. In this case, we observed how Digital ICAR quickly aggregated a large number of actors who made the relationship from lower network diversity to higher diversity due to the relative transparency among actors. Consistent with research on network interdependency (Van Der Vegt et al., 2015), our empirical observation indicates mindful knowledge sharing and recombination between separate groups, allowing information to be exchanged in a broader network, resulting in unique and novel opportunities outside the industry experience. Furthermore, rather than a partnership that takes a relatively long time (Zafari et al., 2020), the cooperation indicated in the case was established rapidly due to the visibility and transparency afforded by digital innovation. We also extend the informal control of relationships (Michaelis et al., 2021; Zafari et al., 2020) by exemplifying how mindful control solutions, such as selective sharing, partial co-competition, and multi-homing, might effectively facilitate a venture to secure its benefit during the collective sharing process.

The third mechanism of swift resilience refers to rapid pivoting, the process by which a venture alertly monitors external environments and minimizes the time gap between opportunity identification and new value-in-use development. Consistent with existing mindfulness literature that emphasizes the frequent questioning of the existing assumption and considers alternatives (Vogus \& Sutcliffe, 2012; Weick et al., 1999; Weick \& Sutcliffe, 2007), this research showcases that a venture mindfully engages in various concurrent, strategic addition and exit processes within a limited period. Our case indicates that the heterogeneous resources afforded by the convergence of digital innovation made Digital ICAR able to efficiently alleviate the burden of heavy assets and capture new opportunities bolstered by the crisis, as well as simultaneously avoid less fruitful results through an inevitable setback. Moreover, departing from most ventures that reactively launch a pivot (Hampel et al., 2020; Kirtley \& O'Mahony, 2020), we extend the existing literature on pivoting by highlighting the importance of proactive and rapid pivoting and how they play out in recovery from a crisis. Further, our research speaks to recent observations in pivoting literature, where scholars such as Morgan et al. (2020) emphasize the difference of nearby pivots (when a venture leverages existing resources and capabilities to move into a related product category) and distant pivots (when a venture seeks new resources and capabilities in order to produce completely unrelated products). Our empirical observation paves the way for thinking about the sequence of pivoting by hypothesizing that entrepreneurs are more likely to explore nearby pivots before considering distant pivots during crises. Entrepreneurs could engage in proactive and continuous pivots in a less costly and timeconsuming manner. The reason may be that the number of entrepreneurial agencies becomes larger when pivoting and a venture's digital capability enables it to embrace iterative innovation capability with a marginal cost (Huang et al., 2017; Yoo et al., 2010).

While each mechanism fulfills its distinct purposes, mindfulness driven by digital innovation generates its progressive momentum when each mechanism dynamically interacts with another. For instance, the mechanism of data-driven stretching could yield a meaningful intraorganizational operation foundation as new ventures mindfully reuse existing resources and continuously improvise operations to support new ideas that resonate with the changing circumstances. Guaranteed by data-driven stretching, the mechanism of collective sharing-when viewed from the inter-organization viewpoint - could then openly embrace numerous exchanges when a large number of actors are included. The mechanism of rapid pivoting, drawing upon both intra- and inter-organizational views, is stimulated by collective sharing, whilst having access to heterogeneous resources in a timely manner through the diverse network. By intra-organizational pivoting, we mean the pivots are triggered by the problems and opportunities from the internal operation. The inter-organizational pivots are triggered by problems and opportunities when they interplay with external stakeholders like partners and competitors. As a result, in fast-changing circumstances, entrepreneurs could expand their network diversity and mindfully participate in a variety of changes. In the same way, data-driven stretching-with a close eye on how operations could be further optimized based on emerging opportunities and difficulties-makes the venture continuously alert to details of entrepreneurial opportunities.

The outcome of these choices is swift resilience that particularly focuses on building a new and better equilibrium. The venture assesses its resilience, including not only reestablishing its original operation but also engaging in a robust transformation to create a new equilibrium quickly. In view of the relatively one-sided emphasis on reestablishing existing business in past literature (Doern et al., 2016; Parker \& Ameen, 2018), the research reported here indicates that ventures could embrace new equilibrium quickly when digital innovation is at the core. Our findings reveal that a venture's swift resilience is not 
necessarily mindful resource preparation. Rather, it is mindful organizing of resources enabled by digital innovation that contributes to robust swift transformation. This resilience is largely different from what was previously discussed. In the following section, we specifically explain such swift resilience.

There are notable differences in terms of relationship building, operation structure, and the degree of changes. First, the quick relationship-building among stakeholders for digital ventures is key. Contrary to prior literature, which mentioned relational resources with certain suppliers that required a long time and dedicated effort, albeit strengthening quick resilience (Ambulkar et al., 2015; Craighead et al., 2007), mindful resource organizing behaviors enable new ventures to build quick and flexible relations with a number of heterogeneous partners. Moreover, information asymmetry and transparency, primarily originating from digital innovation (Nambisan et al., 2018), imply that opportunistic behaviors could be monitored and minimized effectively even among a large group of partners. Therefore, swift resilience is potentially extending the scope and scale of relationships and enhancing relationship management effectiveness.

Second, the ongoing mindfulness process stimulated by digital innovation (Briel et al., 2018; Ortiz-de-Mandojana \& Bansal, 2016; Yoo et al., 2010) facilities a venture's ability to effortlessly and quickly adjust business operation. This is different from the existing literature, where being responsive quickly would typically require significant adjustments to organizational structures after a crisis (DesJardine et al., 2019). Moreover, prior studies show that resuming and adapting organizational operations and routines is largely dependent on purposeful leadership initiatives such as managers' previous experience (Haase \& Eberl, 2019; Menéndez Blanco \& Montes-Botella, 2017). In contrast, digital ventures can have quick adaptability through a combination of autonomous and human decision making derived from digital innovation (Rai et al., 2019). Thus, swift resilience occurs with a quick and continuous improvisation process contributed to by efficient decision making.

In addition, the degree of change for resilience outcomes has been considerably different. Previous work regards incremental changes such as quick product alteration (Haase \& Eberl, 2019; Morrish \& Jones, 2020) as an indicator of faster recovery. The degree of change is primarily constrained by the vulnerability and resource scarcity of entrepreneurs during a crisis. In contrast, digital ventures can engage in evolving and dynamic mindfulness that catalyzes a higher possibility for new ventures embracing the wave of innovation (Henfridsson et al., 2014). Consequently, entrepreneurs are more likely to embrace robust transformation as a manner of swift resilience.

\section{Implications}

The theoretical framework, which outlines an emergent process for data-driven stretching, collective sharing, and rapid pivoting, proposes a set of stratagems for building resilience swiftly after a crisis. We find that new ventures can realize swift resilience during a crisis by leveraging digital innovation. We pursue the theoretical and practical implications of that framework and discuss the contributions to resilience, mindfulness, and digital entrepreneurship literature. Responding to the call for new theorizing (Linnenluecke, 2017; Williams et al., 2017), our mindfulness perspective complements earlier research on mindful resource preparation pre-crisis (Powley, 2009; Ramezani \& CamarinhaMatos, 2020; Weick \& Sutcliffe, 2007) by explaining how resilience, particularly a new equilibrium, can be quickly achieved by mindful resource organizing behaviors driven by digital innovation as a crisis occurs. We have introduced mindfulness enabled by digital innovation as a potential driver.

First, the primary contribution of this research is the dynamic process by which ventures embrace mindful resource organizing behaviors driven by digital innovation that ultimately allow swift resilience. In this research, departing from the dominating mindful preparation approach, such as long-term employee relationships (Powley, 2009) and risk averting infrastructures (Ramezani \& Camarinha-Matos, 2020), our findings answer the call for mindful organizing to improve resilience (Williams et al., 2017) and elaborate an alternative view of the success of swift resilience. Specifically, drawing upon prior insights of digital innovation (Henfridsson et al., 2014; Huang et al., 2017; Yoo et al., 2012), we explain how ventures intertwine with three mechanisms, namely, data-driven stretching, collective sharing, and instant pivoting, resulting in doing business unusually quickly. This is particularly imperative for new ventures, significantly influencing their survival (Herbane, 2019). We also offer an initial theoretical attempt to extend the existing literature from research about building resilience quickly (DesJardine et al., 2019; El Baz \& Ruel, 2021) to exploring swift resilience. By explaining the differences between swift resilience and various other quickness-related concepts (e.g., quick decision making, responsiveness) in resilience literature, we have clarified the nature of swift resilience in relationship building, operation structure, and degree changes. The proposed concept of swift resilience can offer guidance to future research on resilience literature.

Second, the result of our study contributes to mindfulness literature (Sutcliffe et al., 2016; Weick \& Sutcliffe, 2006; Weick \& Roberts, 1993). Resonating with the call for mindfulness during a crisis by Williams et al. (2017), these findings allow us to unravel the inner complexity of mindfulness. 
When digital innovation is at the core, the process, the outcome, and the actors of mindfulness have dramatically changed. To be specific, resonating with the cross-level and emergent perspective of mindfulness (Carlo et al., 2012), the process of mindfulness becomes more dynamic with continuous intra- and inter-organizational interactions. The outcome of mindfulness has shifted from recovery to robust transformation with the scope and scale of actors who participate in significant expansion of mindful resource organizing behaviors. Moreover, we extend the intersection of mindfulness and resilience from the cognitive level to the behavioral level. Scholars have predominantly devoted attention to how managers' and employees' mindful mindsets influence resilience (Carlo et al., 2012; Lengnick-Hall \& Beck, 2005; Stoverink et al., 2020). In contrast, less is known about how ventures engage in mindful behaviors to achieve organizational resilience (Sutcliffe et al., 2016). Resonating with the call for a behavior aspect of mindfulness (such as mindful organizing) in threaten-related research (Sutcliffe et al., 2016; Vogus \& Sutcliffe, 2012), this study provides a nuanced picture of entrepreneurs' mindful behaviors shaped by digital innovation that result in swift resilience.

Third, we complement identity change after a crisis in entrepreneurship (Williams \& Shepherd, 2016b). When facing adversity, the identity of a new venture is threatened (Petriglieri, 2011), and entrepreneurial action may provide a vehicle for identity change (Haynie \& Shepherd, 2011; Powell \& Baker, 2014). The identity influences new ventures' day-to-day behaviors that gradually shape the ventures' strategic responses to adversity, ultimately enabling actors to enact who they want to be (Powell \& Baker, 2014; Williams $\&$ Shepherd, 2016a, 2016b). Rather than regaining identification and legitimacy after the pivot (Hampel et al., 2020), this study indicates the importance of proactive engagement with essential external stakeholders, such as partners, during the pivoting process. The case observes the venture change its identity together with its partners, competitors, and customers. Resonating with the call to study how ventures help others impact themselves (Williams \& Shepherd, 2016b), our study supplements existing literature by showing how helping others may benefit a venture's identity changing without penalty. Our case indicates the process by which a venture changes from simply doing business to becoming a platform ecosystem builder who does business with others. Consistent with the notion of compassion venturing (Williams \& Shepherd, 2016a; Williams \& Shepherd, 2020), our case indicates that the prosocial motivation initially took a role enabling the venture to proactively search for a solution that helped others impact themselves. Further, rather than prosocial actions organized by a singular venture, we complement extant literature by illustrating partner-based prosocial activities, such as collective sharing and labor crowdsourcing, with many external ventures, which contribute to the smooth identity change.

With regard to practical implications, this study has at least four implications for managers of firms. First, we provide insights into how ventures alertly seize emerging opportunities to engage in mindful resource organizing behaviors that contribute to robust transformation during a crisis. Rather than preparing resources before a crisis, our model demonstrates that managers can mindfully develop and deploy digital technologies. They can leverage digital technologies such as platform, blockchain, and analytic algorithms to mindfully bootstrap internal and external actors, ultimately resulting in robust transformation. This requires shifting of managerial attention away from the sole focus on controlling available resources at hand to a more mindful exploration of heterogeneous alternatives from the external. Specifically, as our case shows, a venture receives the initial benefit from mindful stretching. Rather than reactively receiving support from the government, entrepreneurs can be more attentive and alert to emerging opportunities and proactively seize an opportunity through the reutilization of existing resources for new purposes. Furthermore, after gaining internal support afforded by digital technologies, ventures can continuously reach out and mindfully mobilize a number of external resources. For example, in the context of this study, managers sought complementary partnerships with competitors and partners without necessarily obtaining the ownership of external resources. Instead, a venture can efficiently forge exchange relationships with a large number of heterogeneous actors within and across the industry boundary. Second, this work might also offer insights for managers to effectively engage in mindful control practice to manage the interdependent relationship with external actors. For example, the finding of this study provides evidence of the importance for managers to share and exchange labor resources during the crisis. It is also encouraging that managers allow partners to use multi-homing. Third, developing the capability to pivot in the face of crisis is a much-needed capability. Often, firms must pivot when it is no other choice. However, the findings of this study indicate that unexpected innovation by uncoordinated actors might also provide productive opportunities for ventures to effectively embrace pivoting. Finally, the results of this study are valuable for managers of firms that seek to make a strategic change during a crisis. Rather than reestablishing legitimacy from stakeholders such as customers and partners after the identity change, managers should become forward-looking to identify methods of shielding their firms from the penalty of identity change. For example, in the context of this study, managers gradually changed their image by working on a 
collective identity with partners and proactively building a pro-social image at the beginning.

\section{Limitations, Future Research, and Conclusions}

Our study has limitations that offer possibilities for future research. First, the insights generated by this study for understanding swift resilience are grounded in our purposive case selection to focus on an extreme digital venture. This choice enabled us to have the unique resources to credibly engage in mindful resource organizing behaviors. Future research can investigate if and how findings from discrete case examples could be integrated to develop insights that are more generalizable to different settings and contexts, such as established ventures. Furthermore, researchers might seek to understand the long-term effects of mindful behaviors after the crisis; how, for instance, mindful practices might imprint onto the organizational culture or contribute to platform sustainability. In addition, following our argument on pivoting, we call for more work to study the emerging literature (Grimes, 2018; Hampel et al., 2020) to unfold the dynamic process of pivoting suited to varying contexts. In the future, scholars might look for opportunities to elaborate in particular on how the mindful organizing dynamics come into play with pivoting.

Potential shortcomings aside, our study shows that such mindful resource organizing behaviors through digital innovation could enable new ventures to achieve resilience swiftly. We have emphasized that mindfulness through digital innovation can extend our understanding of how new ventures can build a new equilibrium effectively during a crisis. In doing so, we hope that our study will raise the critical issue in digital entrepreneurship that continues to inform academe and practice alike.

Acknowledgements This research was supported by National Natural Science Foundation of China (Grant No.71972112, 72101131).

\section{Declarations}

Conflict of interest None.

\section{References}

Ambulkar, S., Blackhurst, J., \& Grawe, S. (2015). Firm's resilience to supply chain disruptions: Scale development and empirical examination. Journal of Operations Management, 33-34, 111-122. https://doi.org/10.1016/j.jom.2014.11.002

Amit, R., \& Han, X. (2017). Value creation through novel resource configurations in a digitally enabled world. Strategic Entrepreneurship Journal, 11(3), 228-242. https://doi.org/10.1002/sej.1256
Akhtar, P., Khan, Z., Tarba, S., \& Jayawickrama, U. (2018). The Internet of Things, dynamic data and information processing capabilities, and operational agility. Technological Forecasting and Social Change, 136, 307-316. https://doi.org/10.1016/j.techfore. 2017.04.023

Badkar, M., \& Greeley, B. (2020). New data shows vast scale of US economic breakdown. Financial Times. https://www.ft.com/conte nt/6361247d-a1df-4a50-b0aa-59395801b3f3. Accessed 15 Apr 2020

Bartz, W., \& Winkler, A. (2016). Flexible or fragile? The growth performance of small and young businesses during the global financial crisis - Evidence from Germany. Journal of Business Venturing, 31(2), 196-215. https://doi.org/10.1016/j.jbusvent. 2015.10.002

Battisti, M., \& Deakins, D. (2017). The relationship between dynamic capabilities, the firm's resource base and performance in a postdisaster environment. International Small Business Journal: Researching Entrepreneurship, 35(1), 78-98. https://doi.org/10. $1177 / 0266242615611471$

Beigi, S. (2014). Mindfulness engineering: a unifying theory of resilience for volatile, uncertain. Complex and Ambiguous (VUCA) World ( $\mathrm{PhD}$ thesis). University of Bristol

Beverland, M., \& Lindgreen, A. (2010). What makes a good case study? A positivist review of qualitative case research published in Industrial Marketing Management, 1971-2006. Industrial Marketing Management, 39(1),56-63. https://doi.org/10.1016/j.indma rman.2008.09.005

Carlo, J. L., Lyytinen, K., Boland, R. J., \& Fitzgerald, F. S. (2012). Dialectics of collective minding: contradictory in a high-risk project. MIS Ouarterly, 36(4), 1081-1108. https://doi.org/10.2307/ 41703499

Chesbrough, H. (2020). To recover faster from Covid-19, open up: Managerial implications from an open innovation perspective. Industrial Marketing Management, 88, 410-413. https://doi.org/ 10.1016/j.indmarman.2020.04.010

Conz, E., \& Magnani, G. (2020). A dynamic perspective on the resilience of firms: A systematic literature review and a framework for future research. European Management Journal, 38(3), 400-412. https://doi.org/10.1016/j.emj.2019.12.004

Craighead, C. W., Blackhurst, J., Rungtusanatham, M. J., \& Handfield, R. B. (2007). The severity of supply chain disruptions: Design characteristics and mitigation capabilities. Decision Sciences, 38(1), 131-156. https://doi.org/10.1111/j.1540-5915.2007. 00151.x

DesJardine, M., Bansal, P., \& Yang, Y. (2019). Bouncing back: building resilience through social and environmental practices in the context of the 2008 global financial crisis. Journal of Management, 45(4), 1434-1460. https://doi.org/10.1177/0149206317708854

Doern, R. (2016). Entrepreneurship and crisis management: The experiences of small businesses during the London 2011 riots. International Small Business Journal: Researching Entrepreneurship, 34(3), 276-302. https://doi.org/10.1177/0266242614553863

Doern, R., Williams, N., \& Vorley, T. (2016). Entrepreneurship and crises: Business as usual? Entrepreneurship and Regional Development, 28(5), 471-475. https://doi.org/10.1080/08985626.2016. 1198091

Drummond, C., O’Toole, T., \& McGrath, H. (2018). Digital engagement strategies and tactics in social media marketing. European Journal of Marketing, 54(6), 1247-1280. https://doi.org/10. 1108/EJM-02-2019-0183

Du, K. (2015). Parenting new acquisitions: Acquirers' digital resource redeployment and targets' performance improvement in the U.S. hospital industry. Information Systems Research, 26(4), 829-844. https://doi.org/10.1287/isre.2015.0604

El Baz, J., \& Ruel, S. (2021). Can supply chain risk management practices mitigate the disruption impacts on supply chains' resilience 
and robustness? Evidence from an empirical survey in a COVID19 outbreak era. International Journal of Production Economics, 233, 107972. https://doi.org/10.1016/j.ijpe.2020.107972

Garud, R., Jain, S., \& Tuertscher, P. (2008). Incomplete by design and designing for incompleteness. Organization Studies, 29(3), 351-371. https://doi.org/10.1177/0170840607088018

Gerring, J. (2007). Case study research: principles and practices. Cambridge University Press

Gibbs, G. R. (2002). Qualitative data analysis: Explorations with NVivo. Open University Press

Gioia, D. A., \& Chittipeddi, K. (1991). Sensemaking and sensegiving in strategic change initiation. Strategic Entrepreneurship Journal, 12(6), 433-448. https://doi.org/10.1002/smj.4250120604

Gioia, D. A., Corley, K. G., \& Hamilton, A. L. (2013). Seeking qualitative rigor in inductive research: notes on the gioia methodology. Organizational Research Methods, 16(1), 15-31. https://doi.org/ 10.1177/1094428112452151

Gittell, J. H., Cameron, K., Lim, S., \& Rivas, V. (2006). Relationships, Layoffs, and organizational resilience: Airline industry responses to september 11. Journal of Applied Behavioral Science, 42(3), 300-329. https://doi.org/10.1177/0021886306286466

Goffin, K., Åhlström, P., Bianchi, M., \& Richtnér, A. (2019). Perspective: state-of-the-art: the quality of case study research in innovation management. Journal of Product Innovation Management, 36(5), 586-615. https://doi.org/10.1111/jpim.12492

Gölgeci, I., \& Kuivalainen, O. (2020). Does social capital matter for supply chain resilience? The role of absorptive capacity and marketing-supply chain management alignment. Industrial Marketing Management, 84, 63-74. https://doi.org/10.1016/j.indma rman.2019.05.006

Grimes, M. G. (2018). The pivot: how founders respond to feedback through idea and identity work. Academy of Management Journal, 61(5), 1692-1717. https://doi.org/10.5465/amj.2015.0823

Gunasekaran, A., Rai, B. K., \& Griffin, M. (2011). Resilience and competitiveness of small and medium size enterprises: An empirical research. International Journal of Production Research, 49(18), 5489-5509. https://doi.org/10.1080/00207543.2011.563831

Haase, A., \& Eberl, P. (2019). The challenges of routinizing for building resilient startups. Journal of Small Business Management, 57(S2), 579-597. https://doi.org/10.1111/jsbm.12511

Hales, D. N., \& Chakravorty, S. S. (2016). Creating high reliability organizations using mindfulness. Journal of Business Research, 69(8), 2873-2881. https://doi.org/10.1016/j.jbusres.2015.12.056

Hampel, C. E., Tracey, P., \& Weber, K. (2020). The art of the pivot: How new ventures manage identification relationships with stakeholders as they change direction. Academy of Management Journal, 63(2), 440-471. https://doi.org/10.5465/amj.2017.0460

Haynie, J. M., \& Shepherd, D. (2011). Toward a theory of discontinuous career transition: Investigating career transitions necessitated by traumatic life events. Journal of Applied Psychology, 96(3), 501-524. https://doi.org/10.1037/a0021450

Henfridsson, O., \& Bygstad, B. (2013). The generative mechanisms of digital infrastructure evolution. MIS Quarterly, 37(3), 907-931. https://doi.org/10.25300/MISQ/2013/37.3.11

Henfridsson, O., Mathiassen, L., \& Svahn, F. (2014). Managing technological change in the digital age: the role of architectural frames. Journal of Information Technology, 29(1), 27-43. https:// doi.org/10.1057/jit.2013.30

Herbane, B. (2015). Threat orientation in small and medium-sized enterprises: Understanding differences toward acute interruptions. Disaster Prevention and Management, 24(5), 583-595. https://doi. org/10.1108/DPM-12-2014-0272

Herbane, B. (2019). Rethinking organizational resilience and strategic renewal in SMEs. Entrepreneurship and Regional Development, 31(5-6), 476-495. https://doi.org/10.1080/08985626. 2018.1541594
Hillmann, J., \& Guenther, E. (2021). Organizational resilience: a valuable construct for management research? International Journal of Management Reviews, 23(1), 7-44. https://doi.org/ 10.1111/ijmr.12239

Huang, J., Henfridsson, O., Liu, M. J., \& Newell, S. (2017). Growing on steroids: rapidly scaling the user base of digital ventures through digital innovation. MIS Quarterly, 41(1), 301-314. https://doi.org/10.25300/MISQ/2017/41.1.16

Kahn, W. A., Barton, M. A., Fisher, C. M., Heaphy, E. D., Reid, E. M., \& Rouse, E. D. (2018). The geography of strain: Organizational resilience as a function of intergroup relations. Academy of Management Review, 43(3), 509-529. https://doi.org/10. 5465/amr.2016.0004

Kirtley, J., \& O'Mahony, S. (2020). What is a pivot? Explaining when and how entrepreneurial firms decide to make strategic change and pivot. Strategic Management Journal,1-34. https:// doi.org/10.1002/smj.3131

Lai, Y., Saridakis, G., Blackburn, R., \& Johnstone, S. (2016). Are the HR responses of small firms different from large firms in times of recession? Journal of Business Venturing, 31(1), 113-131. https://doi.org/10.1016/j.jbusvent.2015.04.005

Langley, A. (1999). Strategies for theorizing from process data. The Academy of Management Review, 24(4), 691-710. https://doi. org/10.5465/amr.1999.2553248

Leguizamon, F., Selva, G., \& Santos, M. (2016). Small farmer suppliers from local to global. Journal of Business Research, 69(10), 4520-4525. https://doi.org/10.1016/j.jbusres.2016.03. 017

Lengnick-Hall, C. A., \& Beck, T. E. (2005). Adaptive fit versus robust transformation: How organizations respond to environmental change. Journal of Management, 31(5), 738-757. https:// doi.org/10.1177/0149206305279367

Locke, K. (2001). Grounded theory in management re-search. SAGE

Li, W., Liu, K., Belitski, M., Ghobadian, A., \& O’Regan, N. (2016). e-Leadership through strategic alignment: An empirical study of small- and medium-sized enterprises in the digital age. Journal of Information Technology, 31(2), 185-206. https://doi.org/10. $1057 /$ jit.2016.10

Linnenluecke, M. K. (2017). Resilience in business and management research: a review of influential publications and a research agenda. International Journal of Management Reviews, 19(1), 4-30. https://doi.org/10.1111/ijmr.12076

Lusch, R. F., \& Nambisan, S. (2015). Service innovation: A service-dominant logic perspective. MIS Quarterly: Management Information Systems, 39(1), 155-175. https://doi.org/10.25300/ MISQ/2015/39.1.07

Maanen, J. Van (1979). Reclaiming qualitative methods for organizational research: a preface. Administrative Science Quarterly, 24(4), 520-526. https://doi.org/10.2307/2392358

Markman, G. M., \& Venzin, M. (2014). Resilience: Lessons from banks that have braved the economic crisis-And from those that have not. International Business Review, 23(6), 1096-1107. https://doi.org/10.1016/j.ibusrev.2014.06.013

McCarthy, N. (2020). How Covid-19 has impacted the global startup scene. Statist. https://www.statista.com/chart/22134/coronavirus-impact-on-startups/. Accessed 12 Jul 2020

McFarlane, A. C., \& Norris, F. H. (2006). Definitions and concepts in disaster research. In F. H. Norris, S. Galea, M. J. Friedman, \& P. J. Watson (Eds.), Methods for disaster mental health research (pp. 3-19). Guilford Press

Mckinsey (2021). The next normal arrives: trends that will define 2021-and beyond. https://www.mckinsey.com/featured-insig hts/leadership/the-next-normal-arrives-trends-that-will-define2021-and-beyond. Accessed 15 Jan 2021

Menéndez Blanco, J. M., \& Montes-Botella, J. L. (2017). Exploring nurtured company resilience through human capital and human 
resource development: Findings from Spanish manufacturing companies. International Journal of Manpower, 38(5), 661674. https://doi.org/10.1108/IJM-11-2015-0196

Michaelis, T. L., Scheaf, D. J., Carr, J. C., \& Pollack, J. M. (2021). An agentic perspective of resourcefulness: Self-reliant and joint resourcefulness behaviors within the entrepreneurship process. Journal of Business Venturing, December, 106083. https://doi. org/10.1016/j.jbusvent.2020.106083

Morgan, T., Anokhin, S., Ofstein, L., \& Friske, W. (2020). SME response to major exogenous shocks: The bright and dark sides of business model pivoting. International Small Business Journal, 38(5), 369-379. https://doi.org/10.1177/0266242620936590

Morrish, S. C., \& Jones, R. (2020). Post-disaster business recovery: An entrepreneurial marketing perspective. Journal of Business Research, 113, 83-92. https://doi.org/10.1016/j.jbusres.2019.03.041

Nambisan, S. (2017). Digital entrepreneurship: toward a digital technology perspective of entrepreneurship. Entrepreneurship: Theory and Practice, 41(6), 1029-1055. https://doi.org/10.1111/etap. 12254

Nambisan, S., Siegel, D., \& Kenney, M. (2018). On open innovation, platforms, and entrepreneurship. Strategic Entrepreneurship Journal, 12(3), 354-368. https://doi.org/10.1002/sej.1300

Nambisan, S., Wright, M., \& Feldman, M. (2019). The digital transformation of innovation and entrepreneurship: Progress, challenges and key themes. Research Policy, 48(8), 103773. https://doi.org/ 10.1016/j.respol.2019.03.018

Nasiri, M., Saunila, M., Ukko, J., Rantala, T., \& Rantanen, H. (2020). Shaping digital innovation via digital-related capabilities. Information Systems Frontiers, 1-18. https://doi.org/10.1007/ s10796-020-10089-2

Ndubisi, N. O., \& Al-Shuridah, O. (2019). Organizational mindfulness, mindful organizing, and environmental and resource sustainability. Business Strategy and the Environment, 28(3), 436-446. https://doi.org/10.1002/bse.2219

Oehmen, J., Locatelli, G., Wied, M., \& Willumsen, P. (2020). Risk, uncertainty, ignorance and myopia: Their managerial implications for B2B firms. Industrial Marketing Management, 88, 330-338. https://doi.org/10.1016/j.indmarman.2020.05.018

Ortiz-de-Mandojana, N., \& Bansal, P. (2016). The long-term benefits of organizational resilience through sustainable business practices. Strategic Management Journal, 37(8), 1615-1631. https://doi.org/ $10.1002 / \mathrm{smj} .2410$

Papazafeiropoulou, A., \& Spanaki, K. (2016). Understanding governance, risk and compliance information systems (GRC IS): The experts view. Information Systems Frontiers, 18(6), 1251-1263. https://doi.org/10.1007/s10796-015-9572-3

Parker, H., \& Ameen, K. (2018). The role of resilience capabilities in shaping how firms respond to disruptions. Journal of Business Research, 88, 535-541. https://doi.org/10.1016/j.jbusres.2017. 12.022

Petriglieri, J. L. (2011). Under threat: Responses to and the consequences of threats to individuals' identities. Academy of Management Review, 36(4), 641-662. https://doi.org/10.5465/amr.2009. 0087

Pillai, S. D., Goldfarb, B., \& Kirsch, D. A. (2020). The origins of firm strategy: Learning by economic experimentation and strategic pivots in the early automobile industry. Strategic Management Journal, 41(3), 369-399. https://doi.org/10.1002/smj.3102

Powell, E. E., \& Baker, T. (2014). It's what you make of it: Founder identity and enacting strategic responses to adversity. Academy of Management Journal, 57(5), 1406-1433. https://doi.org/10.5465/ amj.2012.0454

Powley, E. H. (2009). Reclaiming resilience and safety: Resilience activation in the critical period of crisis. Human Relations, 62(9), 1289-1326. https://doi.org/10.1177/0018726709334881
Rai, A., Constantinides, P., \& Sarker, S. (2019). Next-generation digital platforms: toward human-AI hybrids editor's comments. MIS Quarterly, 43(1), iii-ix. https://dl.acm.org/doi/10.5555/3370135. 3370136

Ramezani, J., \& Camarinha-Matos, L. M. (2020). Approaches for resilience and antifragility in collaborative business ecosystems. Technological Forecasting and Social Change, 151, 119846. https:// doi.org/10.1016/j.techfore.2019.119846

Salovaara, A., Lyytinen, K., \& Penttinen, E. (2019). High reliability in digital organizing: Mindlessness, the frame problem, and digital operations. MIS Quarterly: Management Information Systems, 43(2), 555-578. https://doi.org/10.25300/MISQ/2019/14577

Shepherd, D. A. (2020). COVID 19 and entrepreneurship: time to pivot? Journal of Management Studies, 57(8), 1750-1753. https:// doi.org/10.1111/joms. 12633

Singh, P., Dwivedi, Y. K., Kahlon, K. S., Sawhney, R. S., Alalwan, A. A., \& Rana, N. P. (2020). Smart monitoring and controlling of government policies using social media and cloud computing. Information Systems Frontiers, 22(2), 315-337. https://doi.org/ 10.1007/s10796-019-09916-y

Singh, S. K., Vrontis, D., \& Christofi, M. (2021). What makes mindful self-initiated expatriates bounce back, improvise and perform: Empirical evidence from the emerging Markets. European Management Review, 1-13. https://doi.org/10.1111/emre.12456

Stoverink, A. C., Kirkman, B. L., Mistry, S., \& Rosen, B. (2020). Bouncing back together: Toward a theoretical model of work team resilience. Academy of Management Review, 45(2), 395-422. https://doi.org/10.5465/amr.2017.0005

Spagnoletti, P., Ceci, F., \& Bygstad, B. (2021). Online black-markets: An investigation of a digital infrastructure in the dark. Information Systems Frontiers, 1-16. https://doi-org.ezproxy.nottingham.edu. cn/ https://doi.org/10.1007/s10796-021-10187-9

Strauss, A. C., \& Corbin, J. (1998). Basics of qualitative research: Techniques and procedures for developing grounded theory. SAGE

Sutcliffe, K. M., Vogus, T. J., \& Dane, E. (2016). Mindfulness in organizations: a cross-level review. Annual Review of Organizational Psychology and Organizational Behavior, 3, 55-81. https://doi. org/10.1146/annurev-orgpsych-041015-062531

Van Der Vegt, G. S., Essens, P., Wahlström, M., \& George, G. (2015). From the editors managing risk and resilience. Academy of Management Journal, 58(4), 971-980. https://doi.org/10.5465/amj. 2015.4004

Vogus, T. J., \& Sutcliffe, K. M. (2012). Organizational mindfulness and mindful organizing: A reconciliation and path forward. Academy of Management Learning \& Education, 11(4), 722-735. https:// doi.org/10.5465/amle.2011.0002c

Vogus, T. J., Rothman, N. B., Sutcliffe, K. M., \& Weick, K. E. (2014). The affective foundations of high-reliability organizing. Journal of Organizational Behavior, 35, 592-596. https://doi.org/10.1002/ job

von Briel, F., Davidsson, P., \& Recker, J. (2018). Digital technologies as external enablers of new venture creation in the it hardware sector. Entrepreneurship: Theory and Practice, 42(1), 47-69. https:// doi.org/10.1177/1042258717732779

Wareham, J. D., Fox, P., \& Cano Giner, J. L. (2014). Technology ecosystem governance. Organization Science, 25(4), 1195-1215. https://doi.org/10.2139/ssrn.2201688

Weick, K. E., \& Roberts, K. H. (1993). Collective mind in organizations: heedful interrelating on flight decks. Administrative Science Quarterly, 38(3), 357. https://doi.org/10.2307/2393372

Weick, K. E., Sutcliffe, K. M., \& Obstfeld, D. (1999). Organizing for high reliability: Processes of collective mindfulness. In B. M. Staw \& R. I. Sutton (Eds.), Research in organizational behavior (pp. 81-123). JAI Press 
Weick, K. E., \& Sutcliffe, K. M. (2006). Mindfulness and the quality of organizational attention. Organization Science, 17(4), 514-524. https://doi.org/10.1287/orsc.1060.0196

Weick, K. E., \& Sutcliffe, K. M. (2007). Managing the unexpected: Resilient performance in and age of uncertainty (2nd ed.). Jossey-Bass

Williams, T. A., Gruber, D. A., Sutcliffe, K. M., Shepherd, D. A., \& Zhao, E. Y. (2017). Organizational response to adversity: Fusing crisis management and resilience research streams. Academy of Management Annals, 11(2), 733-769. https://doi.org/10.5465/annals.2015.0134

Williams, T. A., \& Shepherd, D. A. (2016a). Building resilience or providing sustenance: Different paths of emergent ventures in the aftermath of the Haiti earthquake. Academy of Management Journal, 59(6), 2069-2102. https://doi.org/10.5465/amj.2015.0682

Williams, T. A., \& Shepherd, D. A. (2016b). Victim entrepreneurs doing well by doing good: Venture creation and well-being in the aftermath of a resource shock. Journal of Business Venturing, 31(4), 365-387. https://doi.org/10.1016/j.jbusvent.2016.04.002
Yin, R. K. (2009). Case study research, design and method. Sage Publications Ltd

Yoo, Y., Boland, R. J., Lyytinen, K., \& Majchrzak, A. (2012). Organizing for innovation in the digitized world. Organization Science, 23(5), 1398-1408. https://doi.org/10.1287/orsc.1120.0771

Yoo, Y., Henfridsson, O., \& Lyytinen, K. (2010). The new organizing logic of digital innovation: An agenda for information systems research. Information Systems Research, 21(4), 724-735. https:// doi.org/10.1287/isre.1100.0322

Zafari, K., Biggemann, S., \& Garry, T. (2020). Mindful management of relationships during periods of crises: A model of trust, doubt and relational adjustments. Industrial Marketing Management, 88, 278-286. https://doi.org/10.1016/j.indmarman.2020.05.026

Publisher's Note Springer Nature remains neutral with regard to jurisdictional claims in published maps and institutional affiliations. 